\title{
Stereoselective Synthesis of Tetrahydropyran-4-ones from Dioxinones Catalyzed by Scandium(III) Triflate
}

\author{
William J. Morris, Daniel W. Custar, and Karl A. Scheidt* \\ Department of Chemistry, Northwestern University, 2145 Sheridan Road, Evanston, Illinois, \\ 60208
}

\section{Supporting Information}

General Information. All reactions were carried out under a nitrogen atmosphere in flamedried glassware with magnetic stirring. THF, $\mathrm{Et}_{2} \mathrm{O}, \mathrm{CH}_{2} \mathrm{Cl}_{2}, \mathrm{DMF}$ and toluene were purified by passage through a bed of activated alumina. ${ }^{1} \mathrm{CHCl}_{3}$ was purified by passage through a pad of alumina prior to use. Reagents were purified prior to use unless otherwise stated following the guidelines of Perrin and Armarego. ${ }^{2}$ Purification of reaction products was carried out by flash chromatography using EM Reagent silica gel 60 (230-400 mesh). Analytical thin layer chromatography was performed on EM Reagent $0.25 \mathrm{~mm}$ silica gel $60-\mathrm{F}$ plates. Visualization was accomplished with UV light and anisaldehyde, ceric ammonium nitrate stain, potassium permangenate, or phosphomolybic acid followed by heating. Melting points were obtained on a Thomas Hoover capillary melting point apparatus and are uncorrected. Infrared spectra were recorded on a Bio-Rad Win FT-IR Pro spectrometer. ${ }^{1} \mathrm{H}-\mathrm{NMR}$ spectra were recorded on a Varian Inova $500(500 \mathrm{MHz})$ or Mercury $400(400 \mathrm{MHz})$ spectrometer and are reported in ppm using solvent as an internal standard $\left(\mathrm{CDCl}_{3}\right.$ at $\left.7.26 \mathrm{ppm}\right)$. Data are reported as (ap = apparent, $\mathrm{s}$ = singlet, $\mathrm{d}=$ doublet, $\mathrm{t}=$ triplet, $\mathrm{q}=$ quartet, $\mathrm{m}=$ multiplet, $\mathrm{b}=$ broad; coupling constant( $\mathrm{s})$ in $\mathrm{Hz}$; integration. Proton-decoupled ${ }^{13} \mathrm{C}-\mathrm{NMR}$ spectra were recorded on a Varian Inova 500 (125 $\mathrm{MHz})$ or Mercury $400(100 \mathrm{MHz})$ spectrometer and are reported in ppm using solvent as an internal standard $\left(\mathrm{CDCl}_{3}\right.$ at $\left.77.0 \mathrm{ppm}\right)$. Electrospray mass spectra (ESI-MS) were obtained using Micromass Quattro II Triple Quadrupole Mass Spectrometer.

\section{General Procedure for $\mathrm{Sc}(\mathrm{OTf})_{3}$-catalyzed cyclizations:}

A $10 \mathrm{~mL}$ round bottom flask was charged with powdered $\mathrm{CaSO}_{4}(3 \mathrm{mmol}, 15$ equiv $)$ and flamedried prior to use. $\mathrm{Sc}(\mathrm{OTf})_{3}(0.02 \mathrm{mmol}, 0.1$ equiv $)$ was added to the flask followed by $\mathrm{CH}_{2} \mathrm{Cl}_{2}$ $(1 \mathrm{~mL})$. The aldehyde $\left(0.21 \mathrm{mmol}, 1.05\right.$ equiv) was added and the mixture was cooled to $-10{ }^{\circ} \mathrm{C}$. To this solution was added $\beta$-hydroxy-dioxinone $\left(0.2 \mathrm{mmol}, 1\right.$ equiv) in $\mathrm{CH}_{2} \mathrm{Cl}_{2}(0.5 \mathrm{~mL})$. The reaction was allowed to stir for 4-24 hours before being quenched by the addition of brine ( 5 $\mathrm{mL}$ ) and filtered through a short pad of Celite eluting with $\mathrm{CH}_{2} \mathrm{Cl}_{2}$. The layers were separated and aqueous layer was extracted with EtOAc $(3 \times 2 \mathrm{~mL})$. The combined organic layers were

1. Pangborn, A. B.; Giardello, M. A.; Grubbs, R. H.; Rosen, R. K.; Timmers, F. J. Organometal. 1996, 15, 15181520.

2. Perrin, D. D. and Armarego, W. L. Purification of Laboratory Chemicals; 3rd Ed., Pergamon Press, Oxford. 1988. 
dried over $\mathrm{Na}_{2} \mathrm{SO}_{4}$, filtered, concentrated in vacuo, and purified by flash chromatography to afford cyclized products 3a, 5-14.

\section{General Procedure for One-pot cyclization/Ring Opening:}

A $10 \mathrm{~mL}$ round bottom flask was charged with powdered $\mathrm{CaSO}_{4}(3 \mathrm{mmol}, 15$ equiv) and flamedried prior to use. $\mathrm{Sc}(\mathrm{OTf})_{3}\left(0.04 \mathrm{mmol}, 0.2\right.$ equiv) was added to the flask followed by $\mathrm{CH}_{2} \mathrm{Cl}_{2}$ $(1 \mathrm{~mL})$. The aldehyde $(0.21 \mathrm{mmol}, 1.05$ equiv) was added and the mixture was brought to -10 ${ }^{\circ} \mathrm{C}$. To this solution was added $\beta$-hydroxy-dioxinone $\left(0.2 \mathrm{mmol}, 1\right.$ equiv) in $\mathrm{CH}_{2} \mathrm{Cl}_{2}(0.5 \mathrm{~mL})$. The reaction was allowed to stir until the $\beta$-hydroxy-dioxinone was consumed as visualized by TLC (1-5 hours) at which time the reaction was warmed to $0^{\circ} \mathrm{C}$ and KOEt $(0.8 \mathrm{mmol}, 4$ equiv) was added in one portion. The resulting solution stirred at $0{ }^{\circ} \mathrm{C}$ for 30 minutes and room temperature for 4 hours before being quenched by the addition of brine $(5 \mathrm{~mL})$ and filtered through a pad of Celite. The aqueous layer was extracted with EtOAc ( $3 \times 3 \mathrm{~mL})$ and the combined organic layers were dried over $\mathrm{Na}_{2} \mathrm{SO}_{4}$, filtered and concentrated in vacuo. The residue was purified by flash chromatography to afford tetrahydropyran-4-ones 15-20.
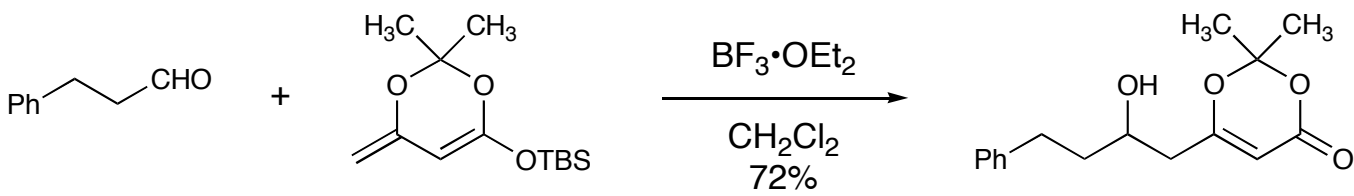

$1 \mathrm{a}$

\section{Preparation of $\beta$-hydroxy-dioxinone 1a:}

To a $-78{ }^{\circ} \mathrm{C}$ solution of silyl dienol ether ${ }^{3}(600 \mathrm{mg}, 2.34 \mathrm{mmol})$, and hydrocinnamaldehyde $(0.1$ $\mathrm{mL}, 0.76 \mathrm{mmol})$, in $\mathrm{CH}_{2} \mathrm{Cl}_{2}(4 \mathrm{~mL})$ was added $\mathrm{BF}_{3} \cdot \mathrm{OEt}_{2}(0.3 \mathrm{~mL}, 2.34 \mathrm{mmol})$ drop-wise over 2 minutes. Reaction was allowed to stir for 4 hours and was quenched with $\mathrm{pH} 7.0$ phosphate buffer $(8 \mathrm{~mL})$. The resulting mixture was extracted with EtOAc $(3 \times 3 \mathrm{~mL})$ and the combined organic layers were dried over $\mathrm{Na}_{2} \mathrm{SO}_{4}$, filtered, concentrated, and purified by flash chromatography to afford 1a. All additional $\beta$-hydroxy-dioxinones were prepared in the same manner.

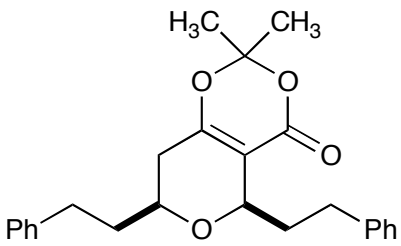

(5,7cis)-7,8-dihydro-2,2-dimethyl-5,7-diphenethylpyrano[4,3d][1,3]dioxin-4(5H)-one: Purified with $30 \%$ ethyl acetate/hexanes, yielding $78 \mathrm{mg}(85 \%)$ of $\mathbf{3 a}$ as a yellow oil. $\mathrm{R}_{f}=0.61(30 \%$ ethyl acetate/hexanes); IR (film) 3079, 3059, 3026, 2999, 2927, 2858, 1724, 1647, 1495, 1452, $1403 \mathrm{~cm}^{-1} ;{ }^{1} \mathrm{H}$ NMR (500 MHz, $\left.\mathrm{CDCl}_{3}\right) \delta$ 7.33-7.21 $(\mathrm{m}, 10 \mathrm{H}) ; 4.43(\mathrm{~m}, 1 \mathrm{H}), 3.51(\mathrm{~m}, 1 \mathrm{H}) ; 2.88(\mathrm{~m}, 2 \mathrm{H}) ; 2.79(\mathrm{~m}, 2 \mathrm{H})$; $2.50(\mathrm{~m}, 1 \mathrm{H}) ; 2.22(\mathrm{~m}, 1 \mathrm{H}) ; 1.98(\mathrm{~m}, 2 \mathrm{H}) ; 1.85(\mathrm{~m}, 2 \mathrm{H}) ; 1.70(\mathrm{~s}, 3 \mathrm{H}) ; 1.69(\mathrm{~s}, 3 \mathrm{H}) ;{ }^{13} \mathrm{C} \mathrm{NMR}$ $\left(125 \mathrm{MHz}_{\mathrm{CDCl}}\right) \quad \delta 163.7,159.2,142.3,141.6,128.8,128.7,128.6,128.5,126.2,125.9$, 105.9, 105.1, 72.6, 71.5, 37.2, 35.9, 33.8, 31.7, 28.4, 27.8, 22.4; LRMS (ESI): Mass calculated for $\mathrm{C}_{25} \mathrm{H}_{28} \mathrm{O}_{4}[\mathrm{M}+\mathrm{Na}]^{+}$, 415.1. Found 415.7.

3. Denmark, S. E.; Beutner, G. L. J. Am. Chem. Soc. 2003, 125, 7800-7801. 
<smiles>CCCCCCC1OC(CCc2ccccc2)CC2=C1C(=O)OC(C)(C)O2</smiles>
with $30 \%$ ethyl acetate/hexanes, yielding $54 \mathrm{mg}(80 \%)$ of 5 as a yellow oil. $\mathrm{R}_{f}=0.74$ (30\% ethyl acetate/hexanes); IR (film) 3061, 3026, 2997, 2927, 2857, 1727, 1650, 1495, $1403 \mathrm{~cm}^{-1}$;

${ }^{1} \mathrm{H}$ NMR $\left(500 \mathrm{MHz}, \mathrm{CDCl}_{3}\right)$ d 7.30-7.18 (m, $\left.5 \mathrm{H}\right) ; 4.35(\mathrm{~m}, 1 \mathrm{H}) ; 3.44(\mathrm{~m}, 1 \mathrm{H}) ; 2.80(\mathrm{~m}, 1 \mathrm{H})$; $2.74(\mathrm{~m}, 1 \mathrm{H}) ; 2.18-2.04(\mathrm{~m}, 2 \mathrm{H}) ; 1.94(\mathrm{~m}, 1 \mathrm{H}) ; 1.80(\mathrm{~m}, 1 \mathrm{H}) ; 1.68(\mathrm{~s}, 3 \mathrm{H}) ; 1.66(\mathrm{~s}, 3 \mathrm{H}) ; 1.58(\mathrm{~m}$, $4 \mathrm{H}) ; 1.47(\mathrm{~m}, 2 \mathrm{H}) ; 1.30(\mathrm{~m}, 4 \mathrm{H}) ; 0.89(\mathrm{~m}, 3 \mathrm{H}) ;{ }^{13} \mathrm{C}$ NMR $\left(125 \mathrm{MHz}, \mathrm{CDCl}_{3}\right) \delta 163.7,159.8$, $141.7,128.7,128.6,126.2$, 105.8, 105.5, 73.3, 71.3, 37.1, 34.2, 33.7, 32.2, 31.6, 29.5, 27.8, 25.5, 25.4, 22.9, 22.4; LRMS (ESI): Mass calculated for $\mathrm{C}_{23} \mathrm{H}_{32} \mathrm{O}_{4}[\mathrm{M}+\mathrm{Na}]^{+}, 395.5$ Found 395.1.

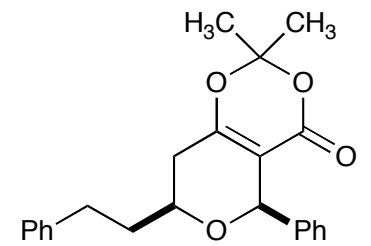

(5,7cis)-7,8-dihydro-2,2-dimethyl-7-phenethyl-5-phenylpyrano[4,3d] [1,3]dioxin-4(5H)-one: Purified with 30\% ethyl acetate/hexanes, yielding $78 \mathrm{mg}(71 \%)$ of 6 as a yellow oil. $\mathrm{R}_{f}=0.48(30 \%$ ethyl acetate/hexanes); IR (film) 3030, 2999, 2936, 2858, 1729, 1652, 1403, $1275 \mathrm{~cm}^{-1} ;{ }^{1} \mathrm{H}$ NMR $\left(500 \mathrm{MHz}, \mathrm{CDCl}_{3}\right) 7.45-7.11(\mathrm{~m}, 10 \mathrm{H}) ; 5.36(\mathrm{~s}, 1 \mathrm{H})$; $3.69(\mathrm{~m}, 1 \mathrm{H}) ; 2.76(\mathrm{~m}, 2 \mathrm{H}) ; 2.44-2.24(\mathrm{~m}, 2 \mathrm{H}) ; 2.02(\mathrm{~m}, 1 \mathrm{H}) ; 1.86(\mathrm{~m}$, $1 \mathrm{H}) ; 1.69(\mathrm{~s}, 3 \mathrm{H}) ; 1.68(\mathrm{~s}, 3 \mathrm{H}) ;{ }^{13} \mathrm{C} \mathrm{NMR}\left(125 \mathrm{MHz}, \mathrm{CDCl}_{3}\right) \quad \delta 163.6,159.2,142.0,140.1$, $128.8,128.7,128.6,128.5,128.3,126.3,106.2,76.1,72.4,36.8,33.7,31.5,27.8,22.9$; LRMS (ESI): Mass calculated for $\mathrm{C}_{23} \mathrm{H}_{24} \mathrm{O}_{4}[\mathrm{M}+\mathrm{Na}]^{+}, 387.4$ Found 387.0.<smiles>CC1(C)OC(=O)C2=C(CC(CCc3ccccc3)O[C@H]2c2ccc(Cl)cc2)O1</smiles>

(5,7cis)-5-(4-chlorophenyl)-7,8-dihydro-2,2-dimethyl-7phenethylpyrano[4,3-d][1,3]dioxin-4(5H)-one: Purified with $30 \%$ ethyl acetate/hexanes, yielding $56 \mathrm{mg}(73 \%)$ of 7 as a yellow oil. $\mathrm{R}_{f}$ $=0.54$ (30\% ethyl acetate/hexanes); IR (film) 3059, 3027, 2997, 2938, 2858, 1728, 1649, 1403, 1275, $1202 \mathrm{~cm}^{-1}$; ${ }^{1} \mathrm{H}$ NMR $(500$ $\left.\mathrm{MHz}, \mathrm{CDCl}_{3}\right)$ 7.38-7.16 (m, 9H); $5.32(\mathrm{~s}, 1 \mathrm{H}) ; 3.68(\mathrm{~m}, 1 \mathrm{H}) ; 2.77$ $(\mathrm{m}, 2 \mathrm{H}) ; 2.38-2.24(\mathrm{~m}, 2 \mathrm{H}) ; 2.03(\mathrm{~m}, 1 \mathrm{H}) ; 1.86(\mathrm{~m}, 1 \mathrm{H}) ; 1.66(\mathrm{~s}$, $3 \mathrm{H}) ; 1.65(\mathrm{~s}, 3 \mathrm{H}) ;{ }^{13} \mathrm{C}$ NMR $\left(125 \mathrm{MHz}, \mathrm{CDCl}_{3}\right) \quad \delta 163.8,159.1,141.3,139.1,134.2,129.6$, $128.8,128.7,128.6,126.3,106.4,105.1,75.4,72.5,36.8,33.6,31.6,27.8,22.9$; LRMS (ESI): Mass calculated for $\mathrm{C}_{23} \mathrm{H}_{23} \mathrm{ClO}_{4}[\mathrm{M}+\mathrm{Na}]^{+}, 422.3$ Found 422.1 .<smiles>CC1(C)OC(=O)C2=C(C[C@H](CCc3ccccc3)O[C@H]2c2ccc(F)cc2)O1</smiles>

(5,7cis)-5-(4-fluorophenyl)-7,8-dihydro-2,2-dimethyl-7phenethylpyrano[4,3- $\boldsymbol{d}][\mathbf{1 , 3}] \operatorname{dioxin}-\mathbf{4}(\mathbf{5 H})$-one: Purified with $30 \%$ ethyl acetate/hexanes, yielding $59 \mathrm{mg}(83 \%)$ of $\mathbf{8}$ as a yellow oil. $\mathrm{R}_{f}$ $=0.56$ (30\% ethyl acetate/hexanes); IR (film) 3060, 2999, 2935, $2858,1728,1649,1510,1400,1275,1219 \mathrm{~cm}^{-1} ;{ }^{1} \mathrm{H}$ NMR $(500 \mathrm{MHz}$, $\left.\mathrm{CDCl}_{3}\right)$ 7.40-7.03 (m, 9H); $5.34(\mathrm{~s}, 1 \mathrm{H}) ; 3.69(\mathrm{~m}, 1 \mathrm{H}) ; 2.80-2.72(\mathrm{~m}$, $2 \mathrm{H}) ; 2.38-2.25(\mathrm{~m}, 2 \mathrm{H}) ; 2.01-1.98(\mathrm{~m}, 1 \mathrm{H}) ; 1.86-1.85(\mathrm{~m}, 1 \mathrm{H}) ; 1.67$ 

$(\mathrm{s}, 6 \mathrm{H}) ;{ }^{13} \mathrm{C} \mathrm{NMR}\left(125 \mathrm{MHz}, \mathrm{CDCl}_{3}\right) \delta 163.8,159.1,141.9,136.5,130.0,129.9,128.8,128.7$, 126.3, 115.6, 115.5, 106.3, 105.3, 75.4, 72.3, 36.9, 33.6, 31.5, 27.6, 22.9; LRMS (ESI): Mass calculated for $\mathrm{C}_{23} \mathrm{H}_{23} \mathrm{FO}_{4}[\mathrm{M}+\mathrm{Na}]^{+}, 405.3$ Found 405.2

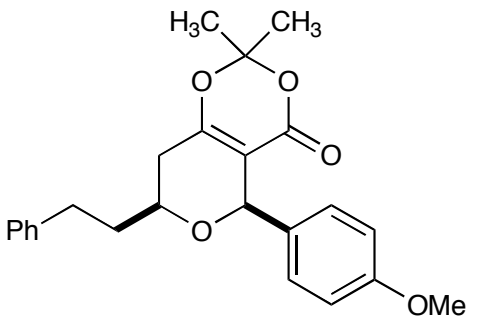

(5,7cis)-7,8-dihydro-5-(4-methoxyphenyl)-2,2-dimethyl-7phenethylpyrano $[4,3-d][1,3]$ dioxin-4(5H)-one: Purified with $30 \%$ ethyl acetate/hexanes, yielding $44 \mathrm{mg}(54 \%)$ of 9 as a yellow oil. $\mathrm{R}_{f}=0.35$ (30\% ethyl acetate/hexanes); IR (film) 2931, 2859, $1728,1652,1512,1403,1273,1248 \mathrm{~cm}^{-1} ;{ }^{1} \mathrm{H}$ NMR $(500 \mathrm{MHz}$, $\left.\mathrm{CDCl}_{3}\right)$ 7.36-7.26 (m, 3H); 7.23-7.18 (m, 4H); 6.92-6.89 (m, 2H); $5.32(\mathrm{~s}, 1 \mathrm{H}) ; 3.80(\mathrm{~s}, 3 \mathrm{H}) ; 3.67(\mathrm{~m}, 1 \mathrm{H}), 2.80(\mathrm{~m}, 2 \mathrm{H}) ; 2.40(\mathrm{~m}$, $1 \mathrm{H}) ; 2.27(\mathrm{~m}, 1 \mathrm{H}) ; 1.99(\mathrm{~m}, 1 \mathrm{H}) ; 1.77(\mathrm{~m}, 1 \mathrm{H}) ; 1.69(\mathrm{~s}, 3 \mathrm{H}) ; 1.67(\mathrm{~s}, 3 \mathrm{H}) ;{ }^{13} \mathrm{C} \mathrm{NMR}(125 \mathrm{MHz}$, $\left.\mathrm{CDCl}_{3}\right) \quad \delta 163.5,159.7,158.9,141.6,132.8,129.3,128.7,128.6,128.5,126.2,114.1,106.2$, 75.6, 72.3, 55.5,36.8, 33.7, 31.5, 27.8, 22.8; LRMS (ESI): Mass calculated for $\mathrm{C}_{24} \mathrm{H}_{26} \mathrm{O}_{5}$ $[\mathrm{M}+\mathrm{Na}]^{+}, 417.4$ Found 417.0

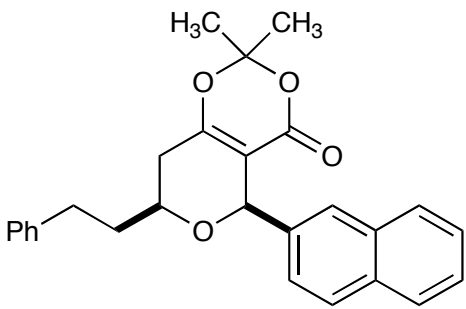

(5,7cis)-7,8-dihydro-2,2-dimethyl-5-(naphthalene-3-yl)-7phenethylpyrano $[4,3-d][1,3]$ dioxin-4(5H)-one: Purified with $30 \%$ ethyl acetate/hexanes, yielding $62 \mathrm{mg}(81 \%)$ of $\mathbf{1 0}$ as a yellow oil. $\mathrm{R}_{f}=0.43$ (30\% ethyl acetate/hexanes); IR (film) 3057, 2998, 2930, 2858, 1727, 1651. 1403, 1267, 1403, 1267, $1203 \mathrm{~cm}^{-1}$; ${ }^{1} \mathrm{H}$ NMR $\left(500 \mathrm{MHz}, \mathrm{CDCl}_{3}\right)$ 7.95-7.20 (m, 12H); $5.55(\mathrm{~s}, 1 \mathrm{H})$; 3.77-3.74 (m, 1H); 2.83-2.75 (m, 2H); 2.41-2.29 (m, 2H); 2.06$2.02(\mathrm{~m}, 2 \mathrm{H}) ; 1.71(\mathrm{~s}, 3 \mathrm{H}) ; 1.68(\mathrm{~s}, 3 \mathrm{H}) ;{ }^{13} \mathrm{C} \mathrm{NMR}\left(125 \mathrm{MHz}, \mathrm{CDCl}_{3}\right) \delta 163.6,141.5,137.8$, 133.6, 133.5, 128.8, 128.7 128.5, 128.4, 128.3, 128.0, 127.8, 126.3,126.2, 126.1,125.5, 106.2, 76.2, 72.4, 36.9, 33.7, 31.5, 27.8, 22.8; LRMS (APCI): Mass calculated for $\mathrm{C}_{27} \mathrm{H}_{26} \mathrm{O}_{4}[\mathrm{M}]^{+}$, 414.5 Found 415.1

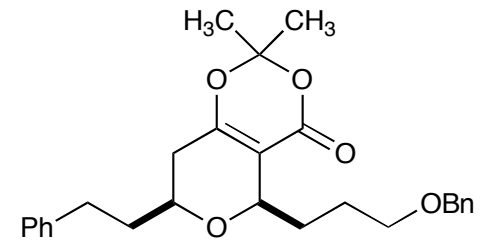

(5;iż)-5-(3-(benzyloxy)propyl)-7,8-dihydro-2,2-dimethyl-5phenethyl-7-phenethylpyrano[4,3- $d][1,3]$ dioxin-4(5H)-one:

Purified with $30 \%$ ethyl acetate/hexanes, yielding $64 \mathrm{mg}(80 \%)$ of 13 as a yellow oil. $\mathrm{R}_{f}=0.50$ (30\% ethyl acetate/hexanes); IR (film) 2929, 2856, 1724, 1647, 1403, 1267, 1204, $1101 \mathrm{~cm}^{-1} ;{ }^{1} \mathrm{H}$ NMR (500 MHz, $\left.\mathrm{CDCl}_{3}\right)$ 7.36-7.17 (m, 10H); $4.53(\mathrm{~s}, 2 \mathrm{H}) ; 4.41-$ $4.40(\mathrm{~d}, 1 \mathrm{H}) ; 3.55-3.44(\mathrm{~m}, 3 \mathrm{H}) ; 2.81-2.78(\mathrm{~m}, 1 \mathrm{H}) ; 2.75-2.71(\mathrm{~m}, 1 \mathrm{H}) ; 2.18-2.10(\mathrm{~m}, 3 \mathrm{H})$; $1.93-$ $1.73(\mathrm{~m}, 5 \mathrm{H}) ; 1.68(\mathrm{~s}, 3 \mathrm{H}) ; 1.66(\mathrm{~s}, 3 \mathrm{H}) ;{ }^{13} \mathrm{C} \mathrm{NMR}\left(125 \mathrm{MHz}, \mathrm{CDCl}_{3}\right) \delta 163.9,159.7,141.6$, $138.8,128.7,128.6,128.5,127.9,127.7,126.2,105.9,105.0,73.1,72.9,71.3,70.7,37.0,33.7$, 31.1, 30.7, 27.7, 25.7, 22.4; LRMS (APCI): Mass calculated for $\mathrm{C}_{27} \mathrm{H}_{32} \mathrm{O}_{5}[\mathrm{M}+\mathrm{H}]^{+}, 436.5$ Found 437.0 


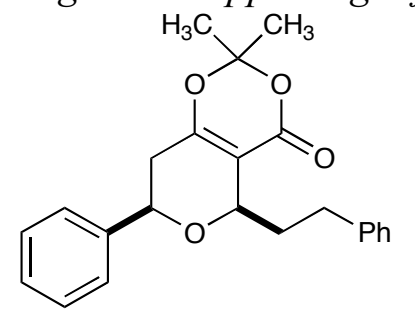

(5,7cis)-7,8-dihydro-2,2-dimethyl-5-phenethyl-7-phenylpyrano[4,3d] [1,3]dioxin-4(5H)-one: Purified with $30 \%$ ethyl acetate/hexanes, yielding $48 \mathrm{mg}(64 \%)$ of 13 as a yellow oil. $\mathrm{R}_{f}=0.57$ (30\% ethyl acetate/hexanes); IR (film) 3061, 3028, 2998, 2926, 2855, 1725, 1650, 1402, 1271, $1204 \mathrm{~cm}^{-1}$; ${ }^{1} \mathrm{H}$ NMR $\left(500 \mathrm{MHz}, \mathrm{CDCl}_{3}\right)$ 7.44-7.16 (m, $10 \mathrm{H}) ; 4.67(\mathrm{~m}, 2 \mathrm{H}) ; 2.86(\mathrm{~m}, 2 \mathrm{H}) ; 2.50(\mathrm{~m}, 3 \mathrm{H}) ; 2.10(\mathrm{~m}, 1 \mathrm{H}) ; 1.73(\mathrm{~s}$, $3 \mathrm{H}) ; 1.72(\mathrm{~s}, 3 \mathrm{H}) ;{ }^{13} \mathrm{C} \mathrm{NMR}\left(125 \mathrm{MHz}, \mathrm{CDCl}_{3}\right) \delta$ 163.6, 159.6, 142.4, $140.9,128.9,128.8,128.5,128.2,125.9,125.8,106.3,104.9,74.2,73.1,35.9,35.5,31.5,27.6$, 22.5; LRMS (ESI): Mass calculated for $\mathrm{C}_{23} \mathrm{H}_{24} \mathrm{O}_{4}[\mathrm{M}+\mathrm{Na}]^{+}, 387.2$ Found 387.4

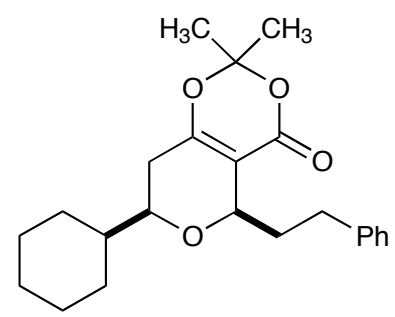

(5,7cis)-7-cyclohexyl-7,8-dihydro-2,2-dimethyl-5phenethylpyrano[4,3-d][1,3]dioxin-4(5H)-one: Purified with $30 \%$ ethyl acetate/hexanes, yielding $52 \mathrm{mg}(70 \%)$ of 14 as a yellow oil. $\mathrm{R}_{f}=$ 0.67 (30\% ethyl acetate/hexanes); IR (film) 3060, 3026, 2998, 2926, 2853, 1727, 1649, 1402, 1267, $1203 \mathrm{~cm}^{-1} ;{ }^{1} \mathrm{H} \mathrm{NMR}\left(500 \mathrm{MHz}, \mathrm{CDCl}_{3}\right)$ 7.28-7.16 (m, 5H); $4.36(\mathrm{~m}, 1 \mathrm{H}) ; 3.25(\mathrm{~m}, 1 \mathrm{H}) ; 2.82(\mathrm{~m}, 1 \mathrm{H}) ; 2.78(\mathrm{~m}$, $1 \mathrm{H}) ; 2.43(\mathrm{~m}, 1 \mathrm{H}) ; 2.21-2.05(\mathrm{~m}, 2 \mathrm{H}) ; 1.88-1.71(\mathrm{~m}, 2 \mathrm{H}) ; 1.68(\mathrm{~s}, 6 \mathrm{H})$; 1.58-1.02 (m, 10H); ${ }^{13} \mathrm{C}$ NMR (125 MHz, $\left.\mathrm{CDCl}_{3}\right) \quad \delta$ 164.4, 159.1, 142.4, 128.8, 128.5, 125.9, $105.9,105.2$, 72.6, 42.6, 35.8, 31.6, 31.4, 29.0, 28.1, 27.6, 26.7, 26.2, 26.0, 22.4; LRMS (ESI): Mass calculated for $\mathrm{C}_{23} \mathrm{H}_{30} \mathrm{O}_{4}[\mathrm{M}+\mathrm{Na}]^{+}, 393.2$ Found 393.4

Note: For tetrahydropyran-4-ones $\mathbf{1 5 - 2 0}$ the reported ${ }^{13} \mathrm{C}$ NMR reflects a mixture of keto:enol tautomers. For ${ }^{1} \mathrm{H}$ spectra, the major constituent (keto tautomer) is reported.

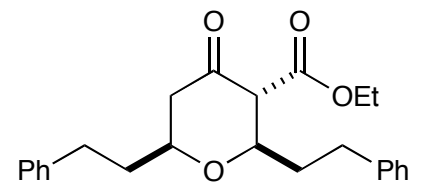

Tetrahydropyran-4-one 15: Purified with 15\% EtOAc/hexanes, yielding $88 \mathrm{mg}(78 \%)$ of 15 as a yellow oil. $\mathrm{R}_{f}=0.55$ (25\% ethyl acetate/hexanes); IR (film) 3026, 2926, 2861, 1741, 1716, 1651, 1603, 1494, 1452, $1126 \mathrm{~cm}^{-1}$; ${ }^{1} \mathrm{H}$ NMR (500 MHz, $\left.\mathrm{CDCl}_{3}\right)$ major:keto tautomer $\delta 7.32-7.21(\mathrm{~m}, 10 \mathrm{H}) ; 4.20(\mathrm{~m}, 2 \mathrm{H}) ; 3.87(\mathrm{~m}, 1 \mathrm{H}) ; 3.60(\mathrm{~m}, 1 \mathrm{H}) ; 3.26(\mathrm{~d}, J=10.7 \mathrm{~Hz}$, $1 \mathrm{H}) ; 2.99(\mathrm{~m}, 1 \mathrm{H}) ; 2.89(\mathrm{~m}, 1 \mathrm{H}) ; 2.79(\mathrm{~m}, 2 \mathrm{H}) ; 2.42-2.20(\mathrm{~m}, 2 \mathrm{H}) ; 2.06-1.81(\mathrm{~m}, 4 \mathrm{H}) ; 1.26(\mathrm{t}, J$ $=7.3 \mathrm{~Hz}, 3 \mathrm{H}) ;{ }^{13} \mathrm{C} \mathrm{NMR}\left(125 \mathrm{MHz}, \mathrm{CDCl}_{3}\right) \quad \delta$ 202.3, 170.9, 168.3, 141.5, 141.4, 128.9, 128.7, 128.6, 128.4, 126.4, 125.4, 77.7, 75.9, 72.2, 70.9, 63.4, 61.4, 60.6, 47.6, 38.1, 36.9, 35.9, 31.9, 32.0, 31.7, 31.3, 14.3; LRMS (APCI): Mass calculated for $\mathrm{C}_{24} \mathrm{H}_{28} \mathrm{O}_{4}[\mathrm{M}]^{+}, 380.2$. Found 380.9.

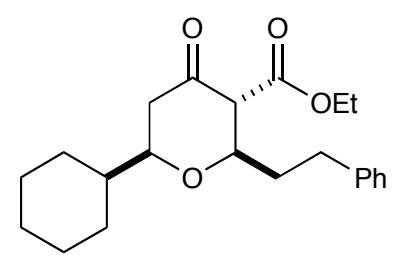

Tetrahydropyran-4-one 16: Purified with 15\% diethyl ether/hexanes, yielding $72 \mathrm{mg}(72 \%)$ of $\mathbf{1 6}$ as a yellow oil. $\mathrm{R}_{f}=0.60(25 \%$ ethyl acetate/hexanes); IR (film) 3061, 3026, 2926, 2853, 1741, 1716, 1653, 1604, $1450 \mathrm{~cm}^{-1} ;{ }^{1} \mathrm{H}$ NMR $\left(500 \mathrm{MHz}, \mathrm{CDCl}_{3}\right)$ major:keto tautomer $\delta 7.30-7.18(\mathrm{~m}, 5 \mathrm{H}) ; 4.16(\mathrm{~m}, 2 \mathrm{H}) ; 3.80(\mathrm{~m} 1 \mathrm{H}) ; 3.38(\mathrm{~m}$, $1 \mathrm{H}) ; 3.23(\mathrm{~d}, J=10.6 \mathrm{~Hz}, 1 \mathrm{H}) ; 2.94(\mathrm{~m}, 1 \mathrm{H}) ; 2.77(\mathrm{~m}, 1 \mathrm{H}) ; 2.52(\mathrm{~m}$, $2 \mathrm{H}) ; 2.05(\mathrm{~m}, 1 \mathrm{H}) ; 1.9-1.4(\mathrm{~m}, 12 \mathrm{H}) ; 1.26(\mathrm{t}, J=7.3 \mathrm{~Hz}, 3 \mathrm{H}) ;{ }^{13} \mathrm{C}$ NMR $\left(125 \mathrm{MHz}, \mathrm{CDCl}_{3}\right) \delta$ 203.3, 171.4, 168.3, 142.9, 141.6, 128.8, 128.7, 128.4, 126.2, 125.7, 81.3, 76.5, 72.2, 63.7, 63.7, 
<smiles>CCOC(=O)[C@H]1C(=O)CC(c2ccccc2)OC1CCc1ccccc1</smiles>

Tetrahydropyran-4-one 17: Purified with $15 \%$ diethyl ether/hexanes, yielding $63 \mathrm{mg}(60 \%)$ of 17 as a yellow oil. $\mathrm{R}_{f}=0.50(25 \%$ ethyl acetate/hexanes); IR (film) 3027, 2980, 2928, 2865, 1742, 1716, 1653, 1494, 1452, $1263 \mathrm{~cm}^{-1}$; ${ }^{1} \mathrm{H}$ NMR $\left(500 \mathrm{MHz}, \mathrm{CDCl}_{3}\right)$ major:keto tautomer $\delta 7.49-7.15(\mathrm{~m}, 10 \mathrm{H}) ; 4.74(\mathrm{dd}, J=2.4,11.5 \mathrm{~Hz}, 1 \mathrm{H}) ; 4.20(\mathrm{~m}$, $2 \mathrm{H}) ; 4.09(\mathrm{~m} \mathrm{1H}) ; 3.41(\mathrm{~d}, J=10.7 \mathrm{~Hz}, 1 \mathrm{H}) ; 2.97(\mathrm{~m}, 1 \mathrm{H}) ; 2.81(\mathrm{~m}, 2 \mathrm{H}) ; 2.60(\mathrm{~m}, 1 \mathrm{H}) ; 2.04(\mathrm{~m}$, $2 \mathrm{H}) ; 1.25(\mathrm{t}, J=7.0, \mathrm{~Hz}, 3 \mathrm{H}) ;{ }^{13} \mathrm{C}$ NMR $\left(125 \mathrm{MHz}, \mathrm{CDCl}_{3}\right) \delta 202.0,168.2,141.5,140.5,128.9$, $128.7,128.4,126.3,125.9,125.7,78.5,78.0,63.2,61.5,48.9,36.8,31.7,14.4$; LRMS (ESI): Mass calculated for $\mathrm{C}_{22} \mathrm{H}_{24} \mathrm{O}_{4}[\mathrm{M}+\mathrm{Na}]^{+}, 375.2$. Found 375.1.

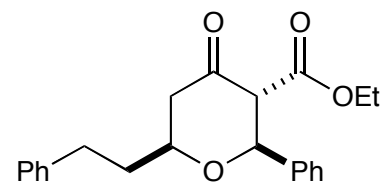

Tetrahydropyran-4-one 18: Purified with 20\% diethyl ether/hexanes, yielding $42 \mathrm{mg}(67 \%)$ of $\mathbf{1 8}$ as a yellow oil. $\mathrm{R}_{f}=0.45(25 \%$ ethyl acetate/hexanes); IR (film) 3028, 2980, 2931, 2864, 1744, 1716, 1653, 1494, $1452 \mathrm{~cm}^{-1}$; ${ }^{1} \mathrm{H}$ NMR $\left(500 \mathrm{MHz}, \mathrm{CDCl}_{3}\right)$ major:keto tautomer $\delta$ 7.44-7.12 (m 10H); 4.89 (d, J = $10.4 \mathrm{~Hz}, 1 \mathrm{H}) ; 4.10(\mathrm{~m}, 2 \mathrm{H}) ; 3.84(\mathrm{~m}, 1 \mathrm{H}) ; 3.60(\mathrm{~d}, J=10.4 \mathrm{~Hz}$, $1 \mathrm{H}) ; 2.79(\mathrm{~m}, 2 \mathrm{H}) ; 2.55-2.32(\mathrm{~m}, 2 \mathrm{H}) ; 1.97-1.80(\mathrm{~m}, 2 \mathrm{H}) ; 1.26(\mathrm{t}, J=7.0 \mathrm{~Hz}, 3 \mathrm{H}) ;{ }^{13} \mathrm{C}$ NMR $(125 \mathrm{MHz}) \delta 202.0,185.2,170.6,167.6,141.3,139.0,128.9,128.8,128.7,128.6,128.4,128.3$, $128.0,127.1,126.3,126.0,81.0,76.8,76.4,72.3,64.7,61.3,60.3,47.9,47.2,37.8,36.9,35.3$, 31.4, 14.2; LRMS (ESI): Mass calculated for $\mathrm{C}_{22} \mathrm{H}_{24} \mathrm{O}_{4}[\mathrm{M}+\mathrm{Na}]^{+}$, 375.2. Found 375.0.

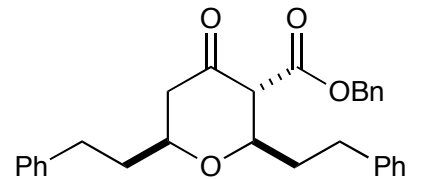

Tetrahydropyran-4-one $\mathbf{1 9}$ Purified with $20 \%$ diethyl ether/hexanes, yielding $80 \mathrm{mg}(82 \%)$ of 19 as an oil. $\mathrm{R}_{f}=0.48(25 \%$ ethyl acetate/hexanes); IR (film) 3061, 3027, 2924, 2862, 1743, 1716, $1653,1603,1494,1452,1336,1257,1124 \mathrm{~cm}^{-1} ;{ }^{1} \mathrm{H}$ NMR $(500 \mathrm{MHz}$, $\left.\mathrm{CDCl}_{3}\right)$ major:keto tautomer $\delta 7.39-7.06(\mathrm{~m}, 15 \mathrm{H}) ; 5.25(\mathrm{~d}, \mathrm{~A}$ of AB system, $J=12.2 \mathrm{~Hz}, 1 \mathrm{H})$; $5.14(\mathrm{~d}, \mathrm{~B}$ of AB system, $J=12.2 \mathrm{~Hz}, 1 \mathrm{H}) ; 3.88(\mathrm{~m}, 1 \mathrm{H}) ; 3.62(\mathrm{~m} 1 \mathrm{H}) ; 3.32(\mathrm{~d}, J=10.7 \mathrm{~Hz}, 1 \mathrm{H})$; $2.92(\mathrm{~m} 2 \mathrm{H}) ; 2.74(\mathrm{~m}, 2 \mathrm{H}) ; 2.47-2.20(\mathrm{~m}, 2 \mathrm{H}) ; 2.00-1.80(\mathrm{~m}, 4 \mathrm{H}) ;{ }^{13} \mathrm{C}$ NMR $\left(125 \mathrm{MHz}, \mathrm{CDCl}_{3}\right)$ ठ $202.1,168.1,141.4,141.3,135.6,128.9,128.8,128.7,128.6,128.5,128.4,126.7,126.2,77.8$, 76.0, 67.2, 63.5, 47.4, 38.1, 36.8, 31.9, 31.7; LRMS (APCI): Mass calculated for $\mathrm{C}_{29} \mathrm{H}_{30} \mathrm{O}_{4}$ [M$\mathrm{H}]^{+}, 441.5$. Found 441.1.

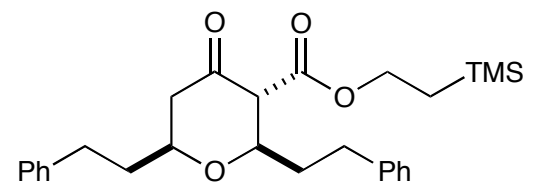
$3.25(\mathrm{~d}, J=10.4 \mathrm{~Hz}, 1 \mathrm{H}) ; 3.02-2.75(\mathrm{~m}, 4 \mathrm{H}) ; 2.47-2.28(\mathrm{~m}, 2 \mathrm{H}) ; 2.06-1.81(\mathrm{~m}, 4 \mathrm{H}) ; 0.89(\mathrm{t}, 2 \mathrm{H})$;
$0.05(\mathrm{~s}, 9 \mathrm{H}) ;{ }^{13} \mathrm{C}$ NMR $\left(125 \mathrm{MHz}, \mathrm{CDCl}_{3}\right) \quad \delta 202.1,171.3,170.7,168.4,142.8,142.0,141.5$, $3.25(\mathrm{~d}, J=10.4 \mathrm{~Hz}, 1 \mathrm{H}) ; 3.02-2.75(\mathrm{~m}, 4 \mathrm{H}) ; 2.47-2.28(\mathrm{~m}, 2 \mathrm{H}) ; 2.06-1.81(\mathrm{~m}, 4 \mathrm{H}) ; 0.89(\mathrm{t}, 2 \mathrm{H})$;
$0.05(\mathrm{~s}, 9 \mathrm{H}) ;{ }^{13} \mathrm{C}$ NMR $\left(125 \mathrm{MHz}, \mathrm{CDCl}_{3}\right) \quad \delta 202.1,171.3,170.7,168.4,142.8,142.0,141.5$,

Tetrahydropyran-4-one 2:0 Purified with $10 \%$ diethyl ether/hexanes, yielding $88 \mathrm{mg}(72 \%)$ of $\mathbf{2 0}$ as an oil. $\mathrm{R}_{f}=0.53$ (25\% ethyl acetate/hexanes); IR (film) 3061, 3026, 2952, 2923, 2862, 1739, 1715, 1651, $1604 \mathrm{~cm}^{-1} ;{ }^{1} \mathrm{H}$ NMR $(500 \mathrm{MHz}$, $\left.\mathrm{CDCl}_{3}\right)$ major:keto tautomer $87.33-7.18(\mathrm{~m}, 10 \mathrm{H}) ; 4.24(\mathrm{~m}, 2 \mathrm{H}) ; 3.88(\mathrm{~m}, 1 \mathrm{H}) ; 3.64(\mathrm{~m}, 1 \mathrm{H})$; 

$63.8,63.5,62.9,47.5,38.1,37.2,36.9,35.6,31.9,31.8,31.7,22.9,17.7,14.3,-1.2$; LRMS (ESI): Mass calculated for $\mathrm{C}_{27} \mathrm{H}_{36} \mathrm{O}_{4} \mathrm{Si}[\mathrm{M}+\mathrm{Na}]^{+}$, 475.3. Found 475.1.

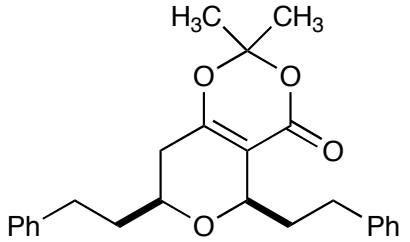

$3 a$

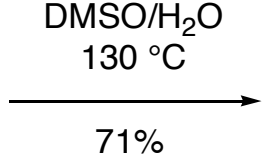

21

\section{Preparation of tetrahydropyran-4-one 21:}

A solution of 3a $(120 \mathrm{mg}, 0.30 \mathrm{mmol})$ in DMSO $(4 \mathrm{~mL})$ and $\mathrm{H}_{2} \mathrm{O}(0.5 \mathrm{~mL})$ was heated to $130{ }^{\circ} \mathrm{C}$ (bath temperature) for 14 hours. The mixture was then cooled to room temperature and diluted with brine $(10 \mathrm{~mL})$ and extracted with EtOAc $(3 \times 3 \mathrm{~mL})$. The combined organic layers were filtered, concentrated and purified by flash chromatography (15\% ethyl acetate/hexanes) to yield $67 \mathrm{mg}$ (71\%) of 21 as a clear oil. $\mathrm{R}_{f}=0.40$ (25\% ethyl acetate/hexanes); IR (film) 3061, 3028, 2924, 2856, 1717, 1494, $1452 \mathrm{~cm}^{-1} ;{ }^{1} \mathrm{H}$ NMR (500 MHz, $\left.\mathrm{CDCl}_{3}\right) \delta$ 7.32-7.19 (m, 10H); 3.54 (m, $2 \mathrm{H}) ; 2.91(\mathrm{~m}, 2 \mathrm{H}) ; 2.78(\mathrm{~m}, 2 \mathrm{H}) ; 2.37-2.25(\mathrm{~m}, 4 \mathrm{H}) ; 2.05(\mathrm{~m}, 2 \mathrm{H}) ; 1.82(\mathrm{~m}, 2 \mathrm{H}) ;{ }^{13} \mathrm{C}$ NMR $(125$ $\left.\mathrm{MHz}, \mathrm{CDCl}_{3}\right) \quad \delta 207.5,141.7,128.7,128.6,126.3,76.0,48.2,38.3,31.9$; LRMS (EI): Mass calculated for $\mathrm{C}_{21} \mathrm{H}_{24} \mathrm{O}_{2}[\mathrm{M}]^{+}$, 308.2. Found 308.0.

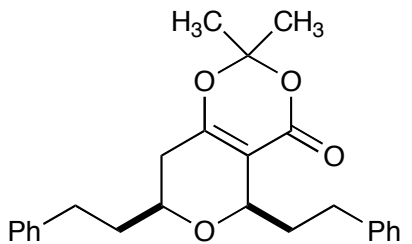

$3 a$

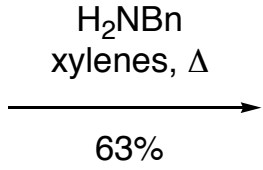

22

\section{Preparation of Amide 22:}

A solution of $3 \mathbf{a}(75 \mathrm{mg}, 0.20 \mathrm{mmol})$ and benzyl amine $(0.4 \mathrm{~mL}, 3.68 \mathrm{mmol})$ in xylenes was vented and submerged into an oil bath that had been preheated to $150{ }^{\circ} \mathrm{C}$. The reaction stirred for 1 hour before being concentrated in vacuo. The crude oil was purified by flash chromatography (30\% ethyl acetate/hexanes) to yield $53 \mathrm{mg}(63 \%)$ of 22 as an oil. $\mathrm{R}_{f}=0.36(25 \%$ ethyl acetate/hexanes); IR (film) 3062, 3026, 2923, 2862, 1718, 1643, 1554, 1496, 1452, $1349 \mathrm{~cm}^{-1}$; ${ }^{1} \mathrm{H}$ NMR $\left(500 \mathrm{MHz}, \mathrm{CDCl}_{3}\right)$ major:keto tautomer $\delta$ 7.40-7.15 (m, 15H); $6.17(\mathrm{~s}, 1 \mathrm{H}) ; 4.51(\mathrm{dd}, \mathrm{A}$ of AB system, $J=5.7,14.9 \mathrm{~Hz}, 1 \mathrm{H}) ; 4.40(\mathrm{dd}, \mathrm{B}$ of AB system, $J=5.7,14.9 \mathrm{~Hz}, 1 \mathrm{H}) ; 3.97(\mathrm{~m}$, $1 \mathrm{H}) ; 3.65(\mathrm{~m}, 1 \mathrm{H}) ; 3.00(\mathrm{~d}, J=10.1 \mathrm{~Hz}, 1 \mathrm{H}) ; 2.99(\mathrm{~m}, 1 \mathrm{H}) ; 2.88(\mathrm{~m}, 1 \mathrm{H}) ; 2.78(\mathrm{~m}, 2 \mathrm{H}) ; 2.43(\mathrm{~m}$, $1 \mathrm{H}) ; 2.26(\mathrm{~m}, 1 \mathrm{H}) ; 2.00(\mathrm{~m}, 2 \mathrm{H}) ; 1.90(\mathrm{~m}, 1 \mathrm{H}) ; 1.80(\mathrm{~m}, 1 \mathrm{H}) ;{ }^{13} \mathrm{C}$ NMR $\left(125 \mathrm{MHz}, \mathrm{CDCl}_{3}\right)$

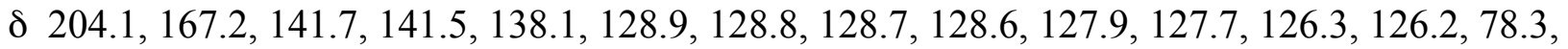



442.3 Found 442.1 .

\section{Preparation of enantioenriched 1a:}

Enantioenriched $\beta$-hydroxy dioxinone 1a was prepared by the procedure previously reported by Denmark. ${ }^{3}$ Enantiomeric excess was determined by analytic HPLC analysis (Chiralcel OD-H, 70:30 Hexanes $/ \mathrm{PrOH}, 1 \mathrm{~mL} / \mathrm{min}, 254 \mathrm{~nm}$ ): $(5 R)$ enantiomer $\mathrm{t}_{\mathrm{r}}=8.7$ min (major), $(5 S)$ enantiomer $\mathrm{t}_{\mathrm{r}}=6.4 \mathrm{~min}$ (minor).

\footnotetext{
${ }^{3}$ Denmark, S. E.; Beutner, G. L. J. Am. Chem. Soc. 2003, 125, 7800-7801.
} 


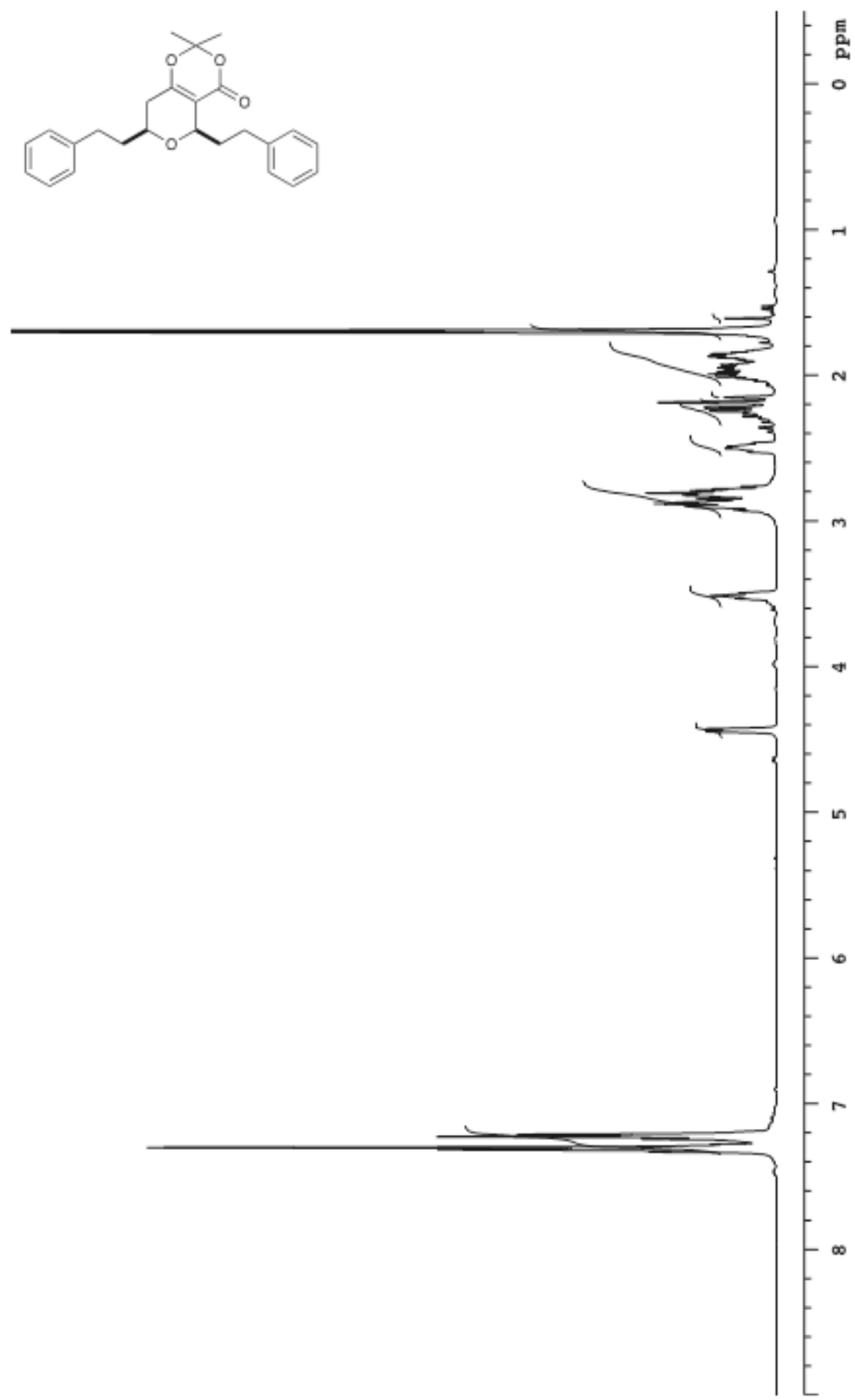




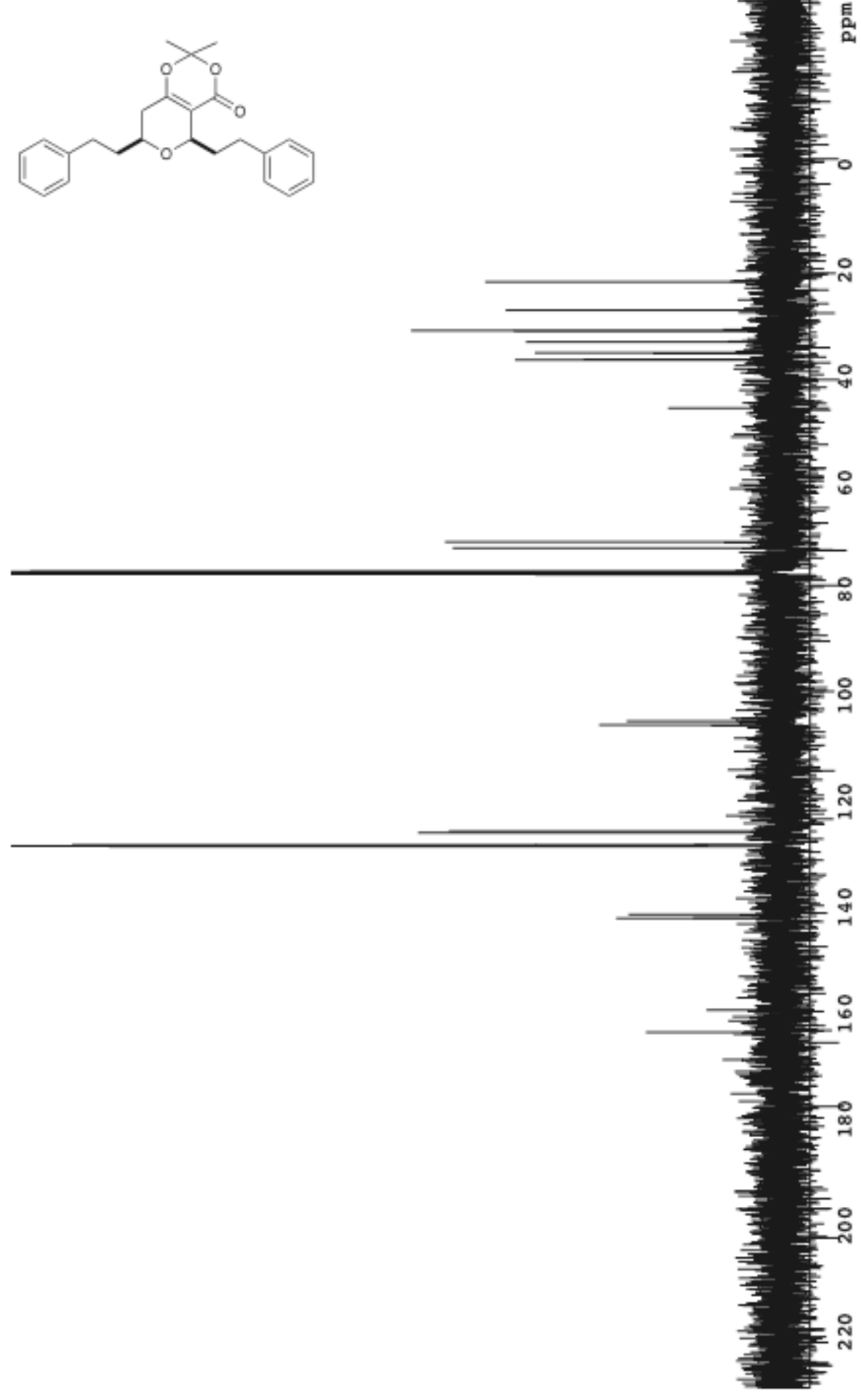




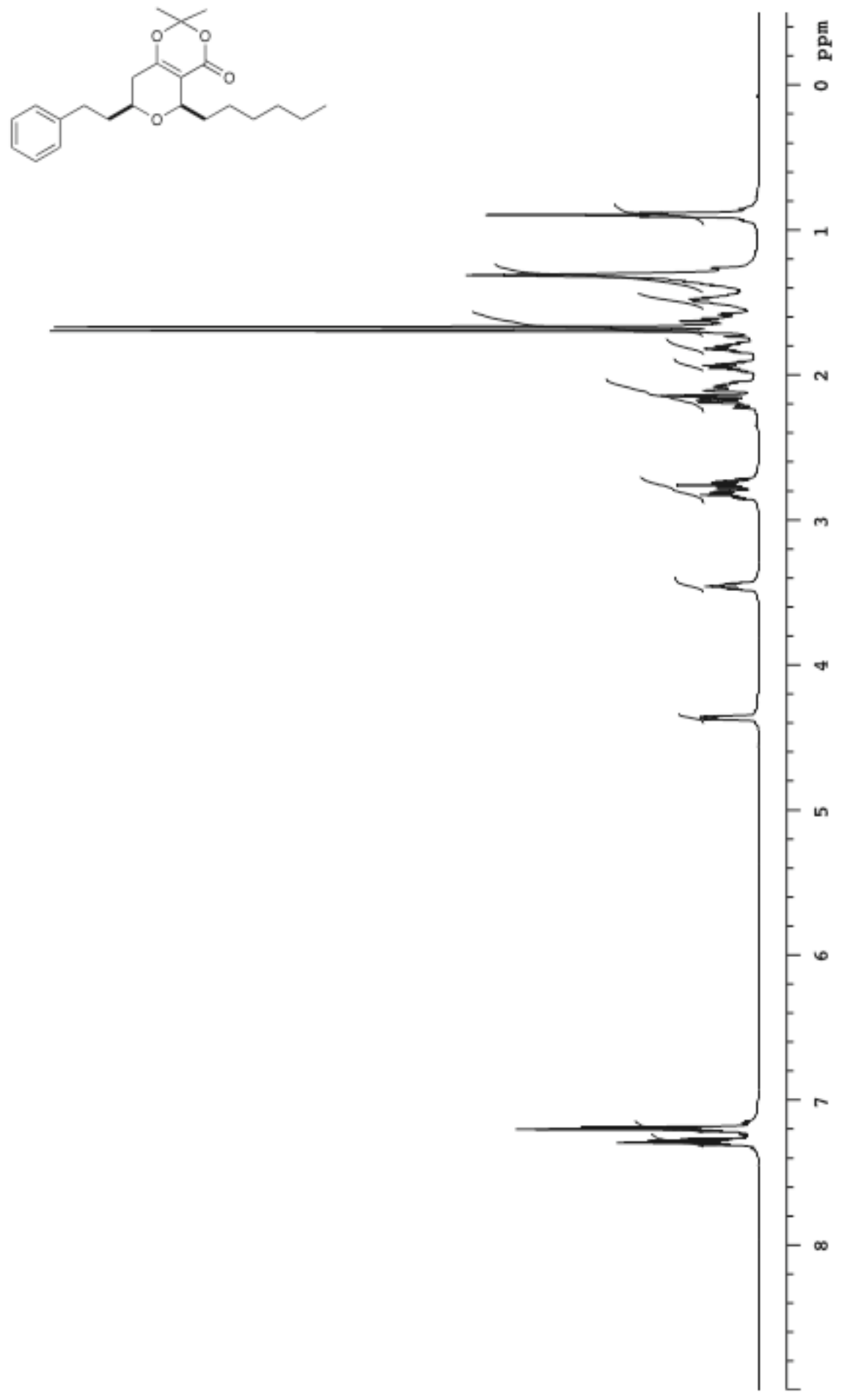




$$
1
$$




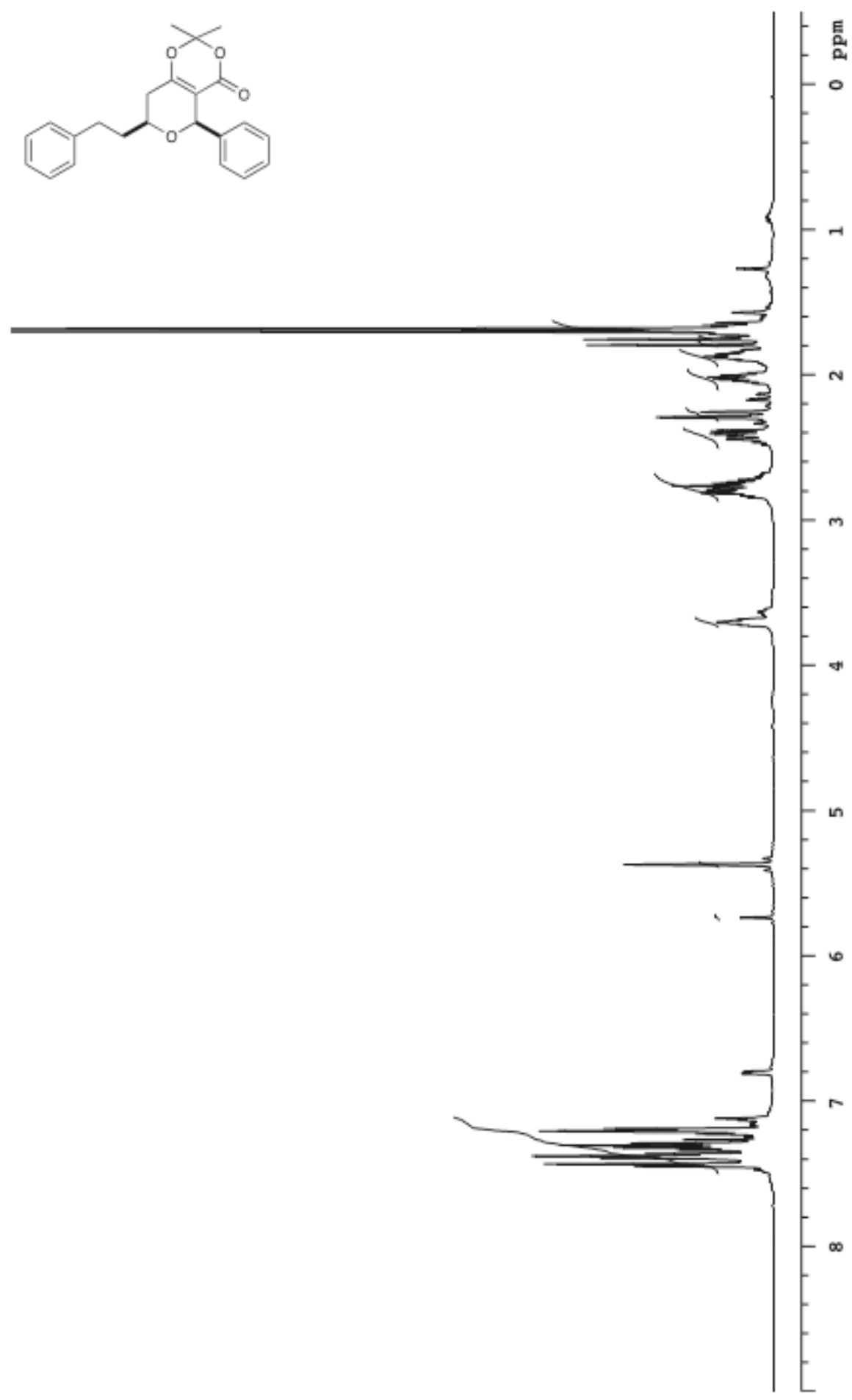



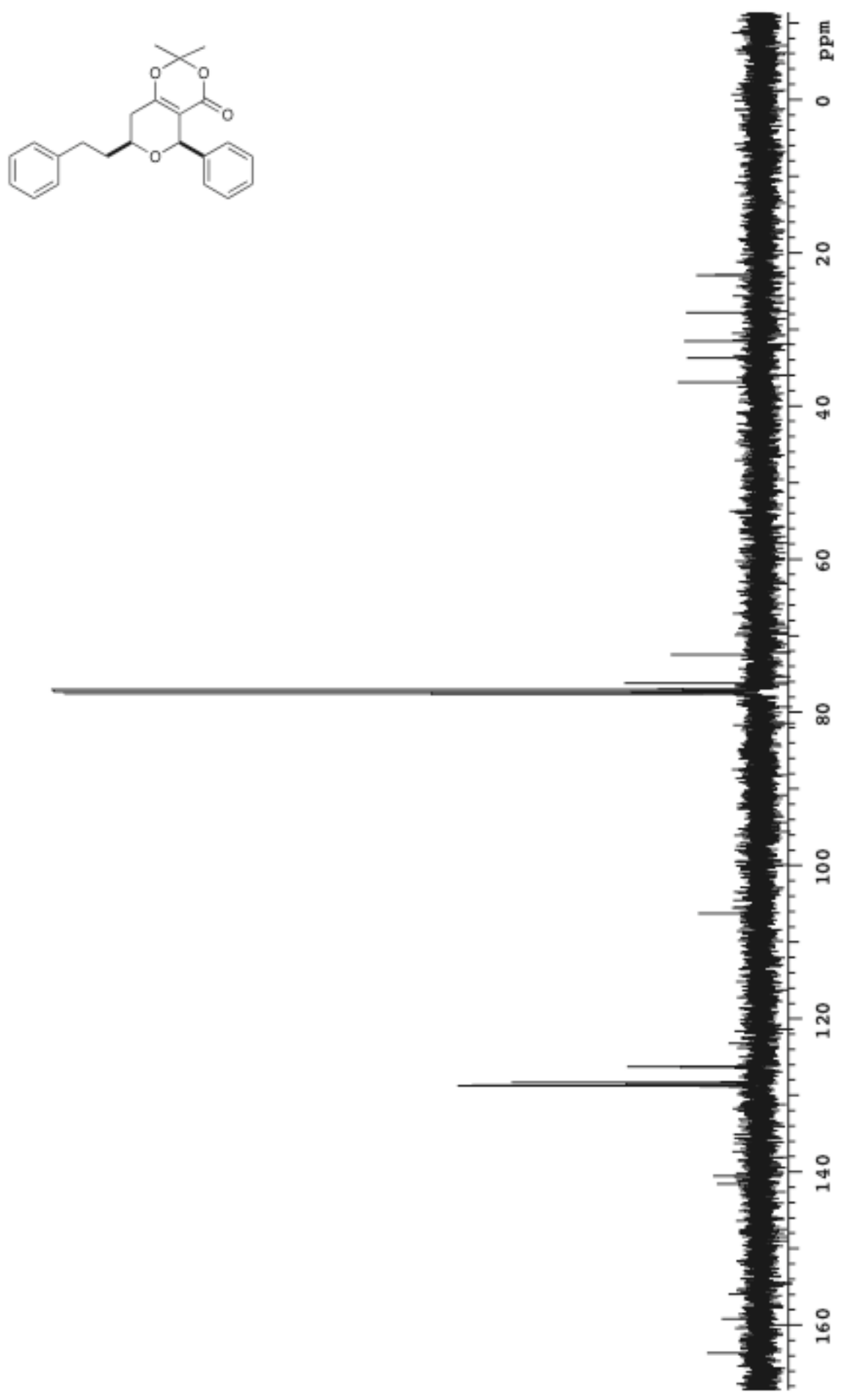


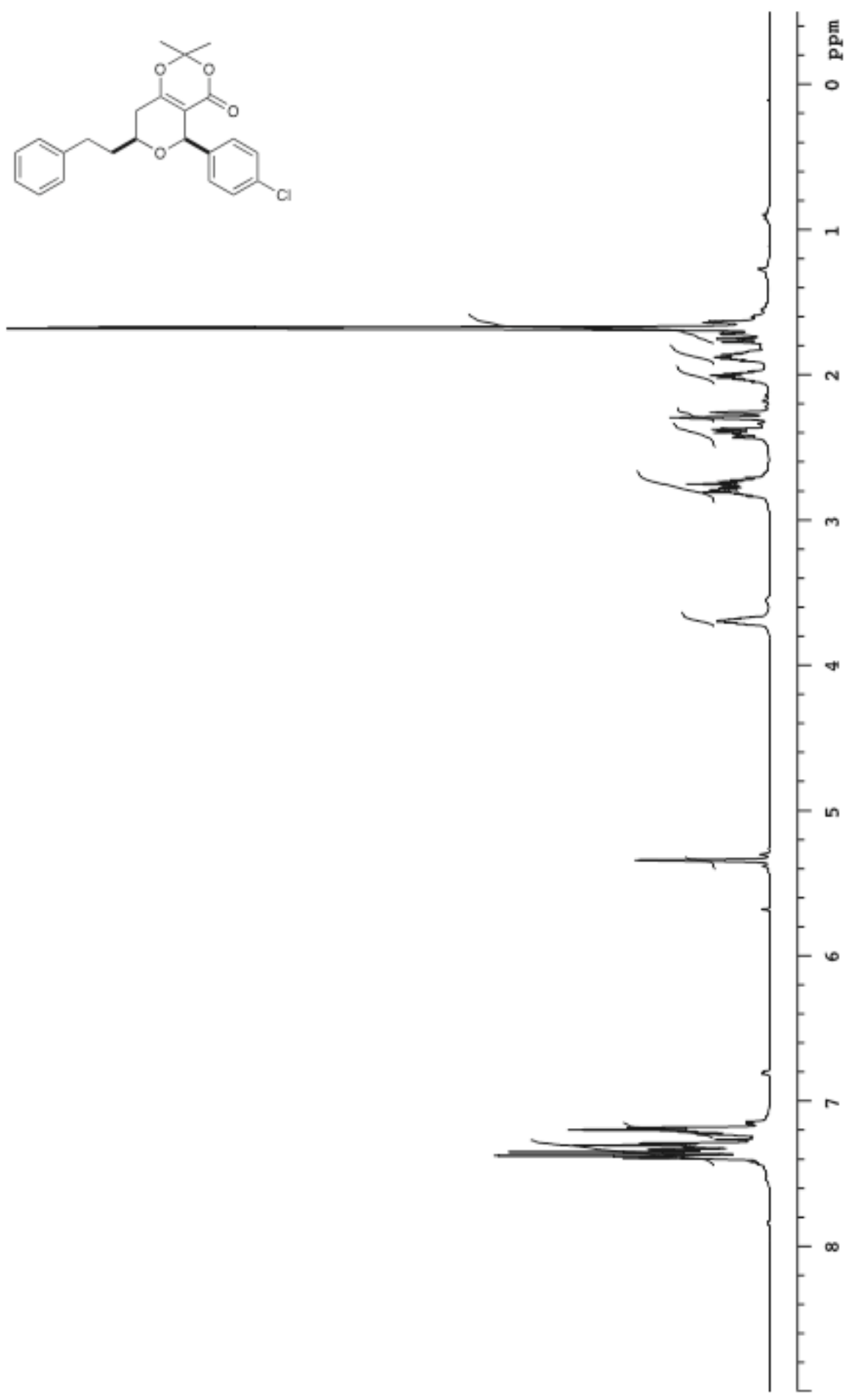




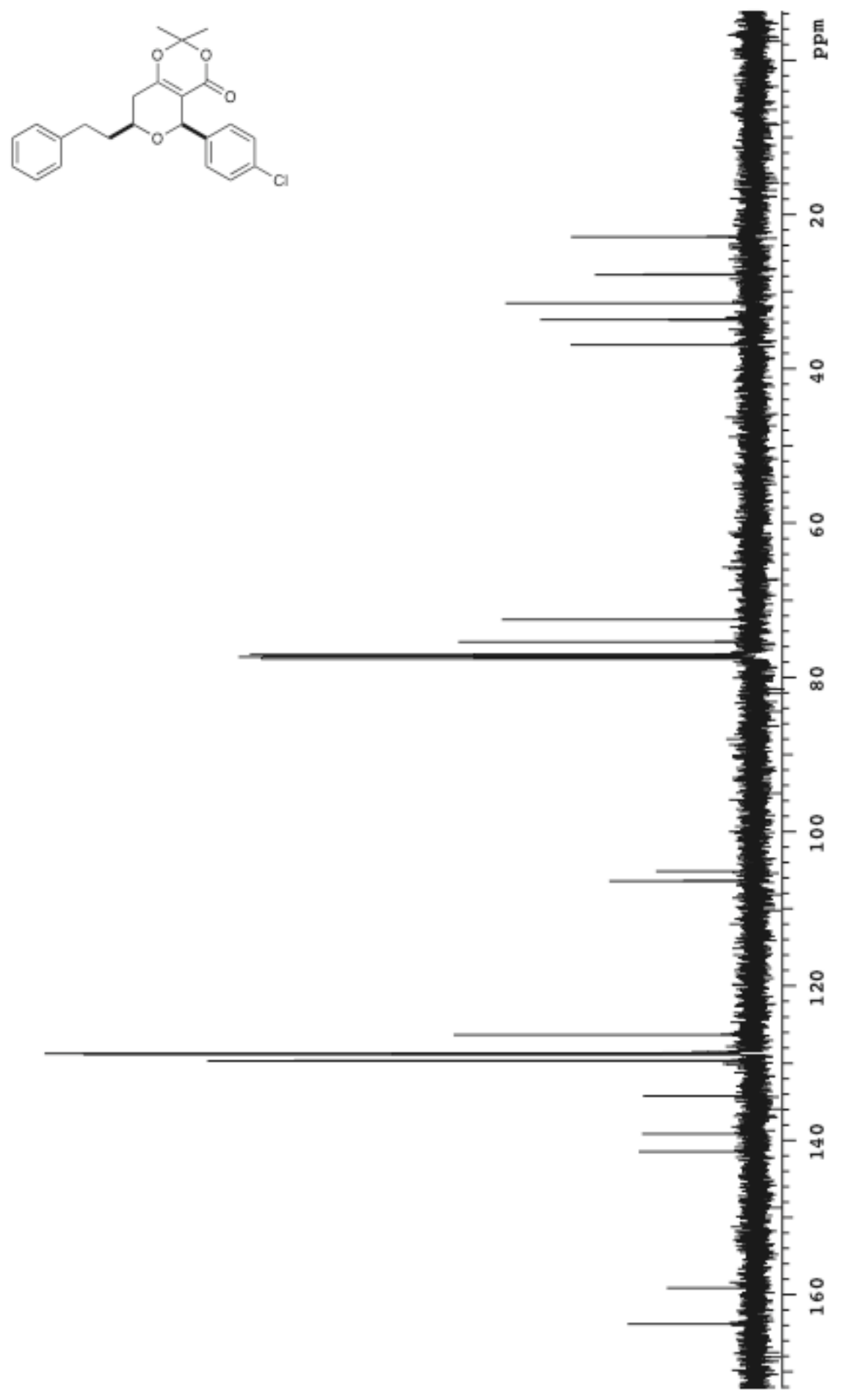



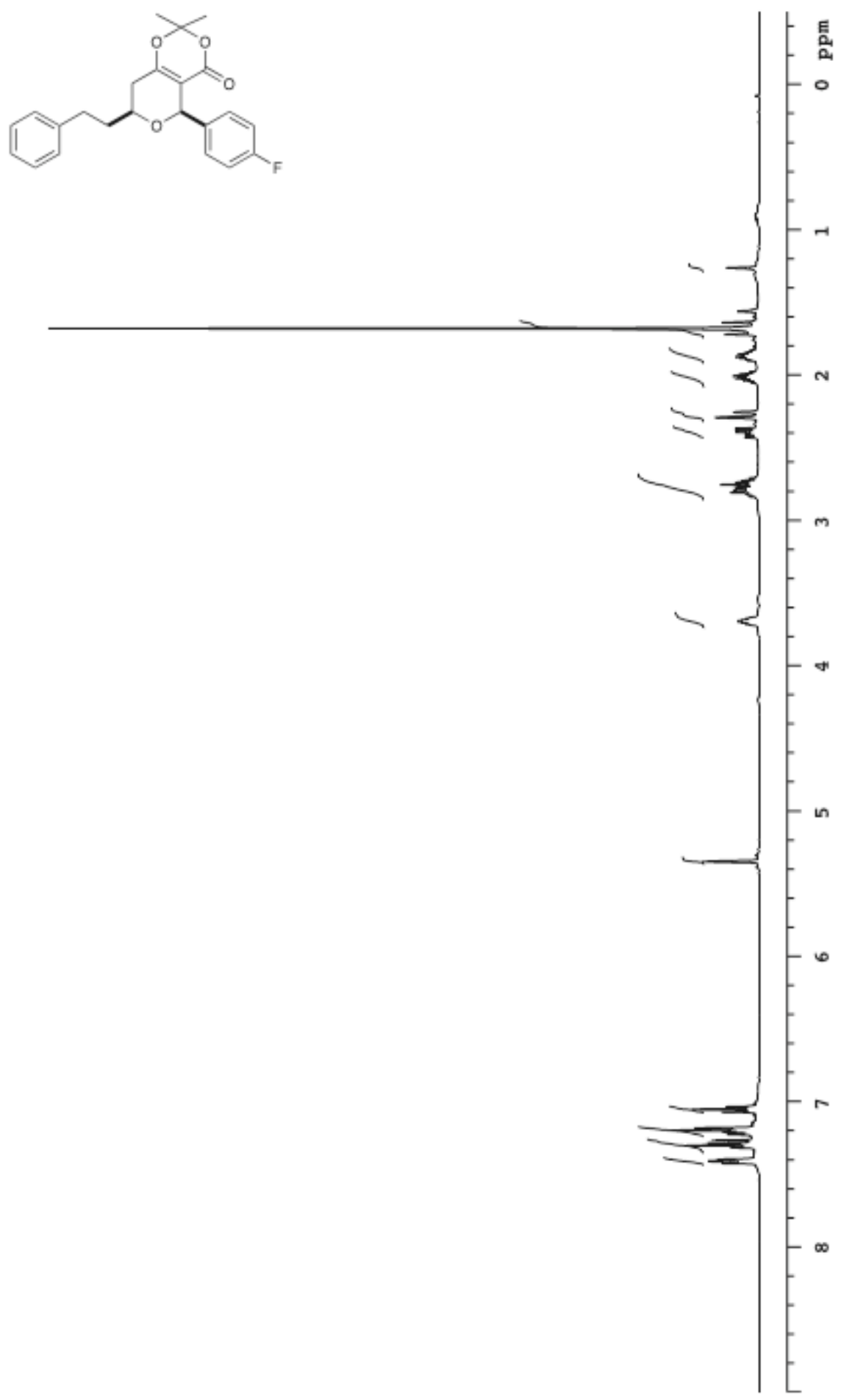


$$
1
$$




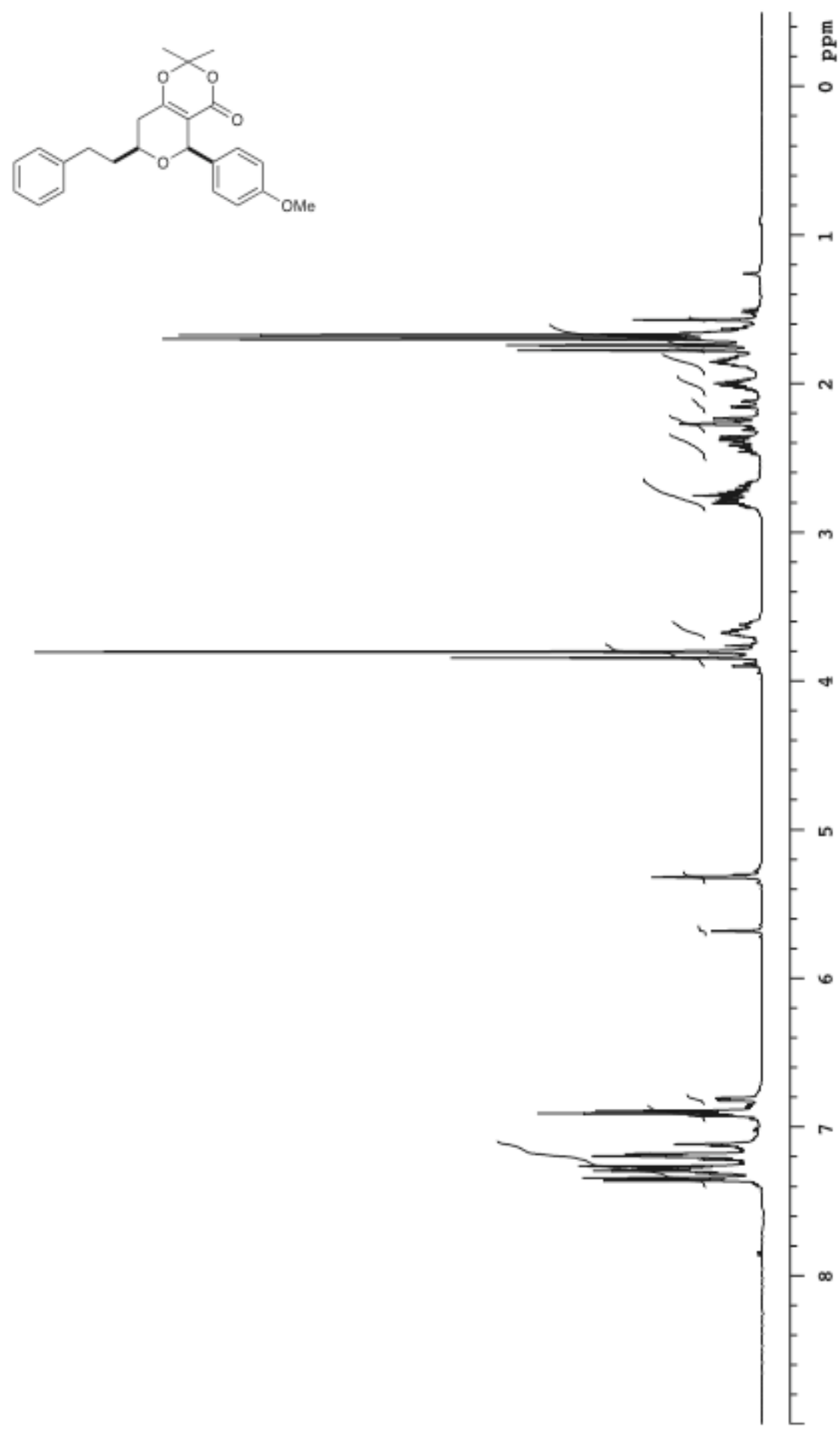




$$
1
$$




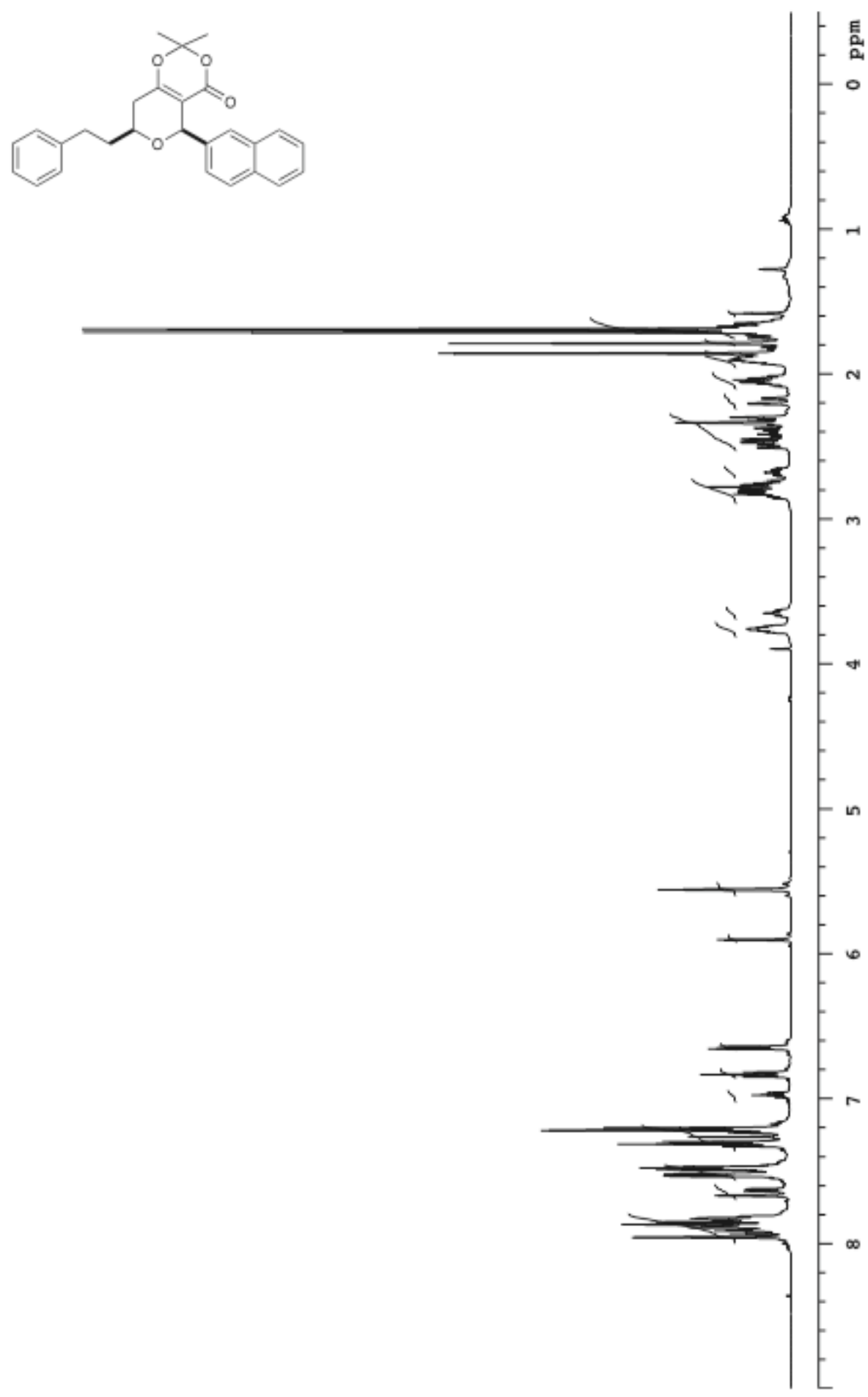



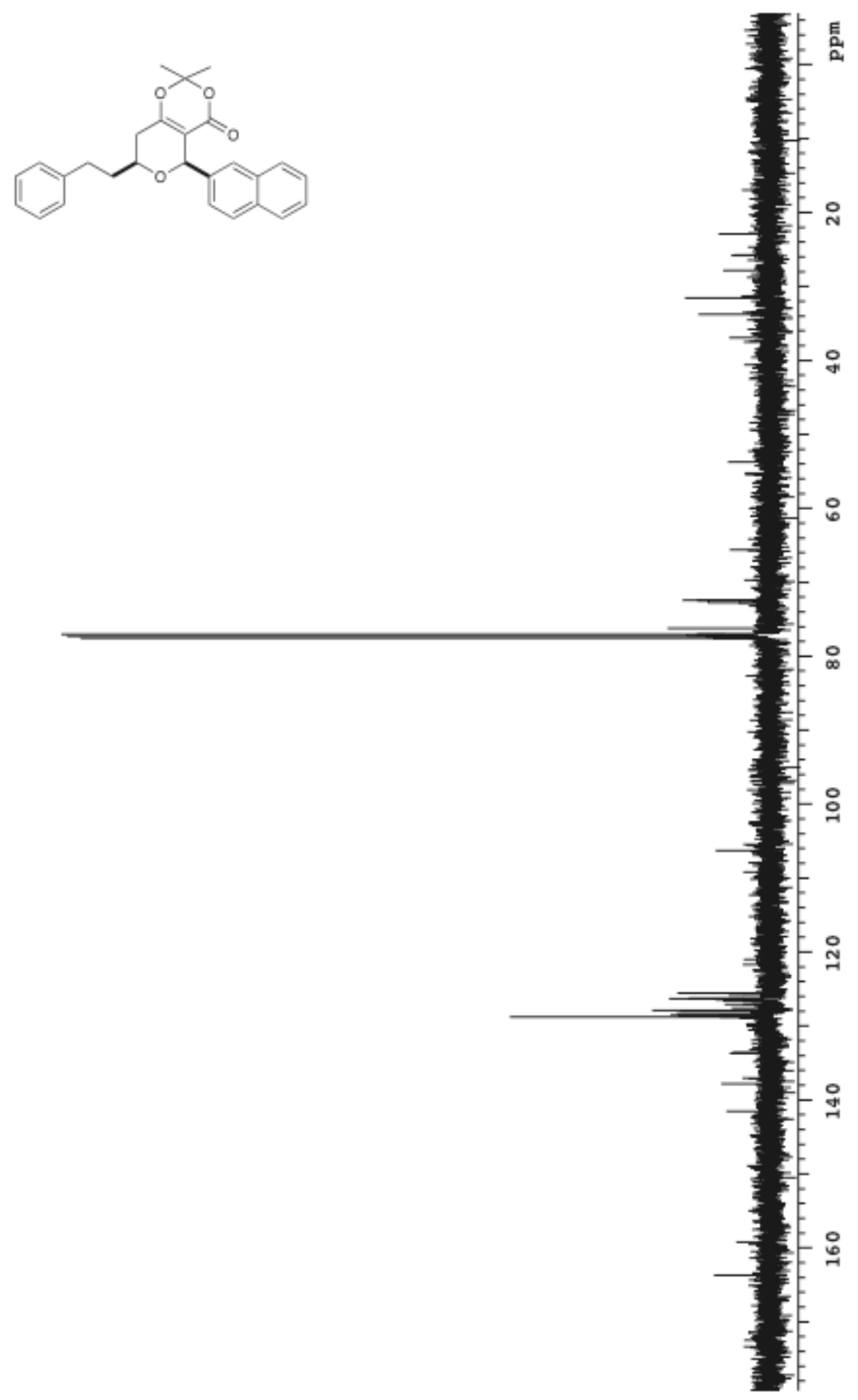


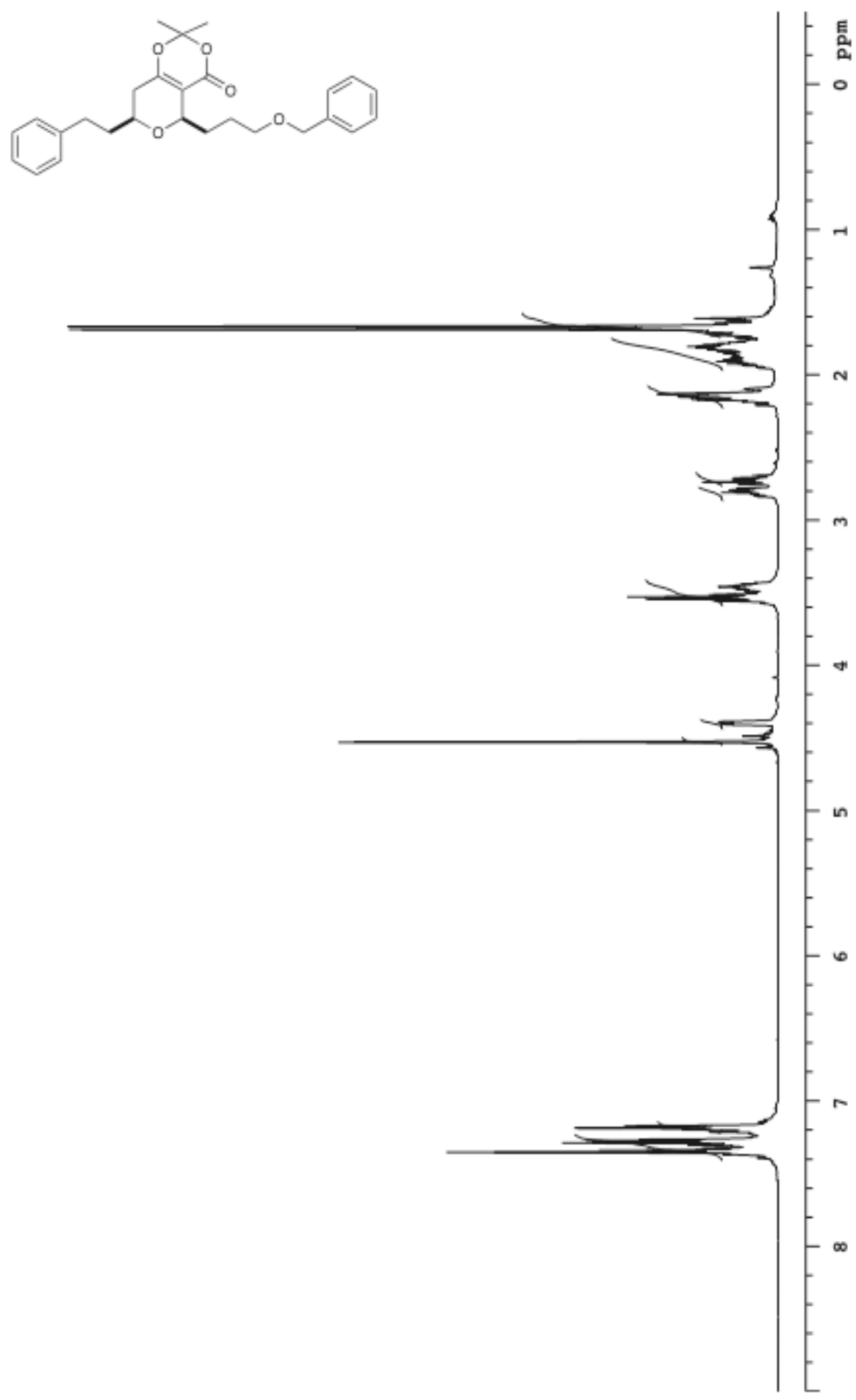



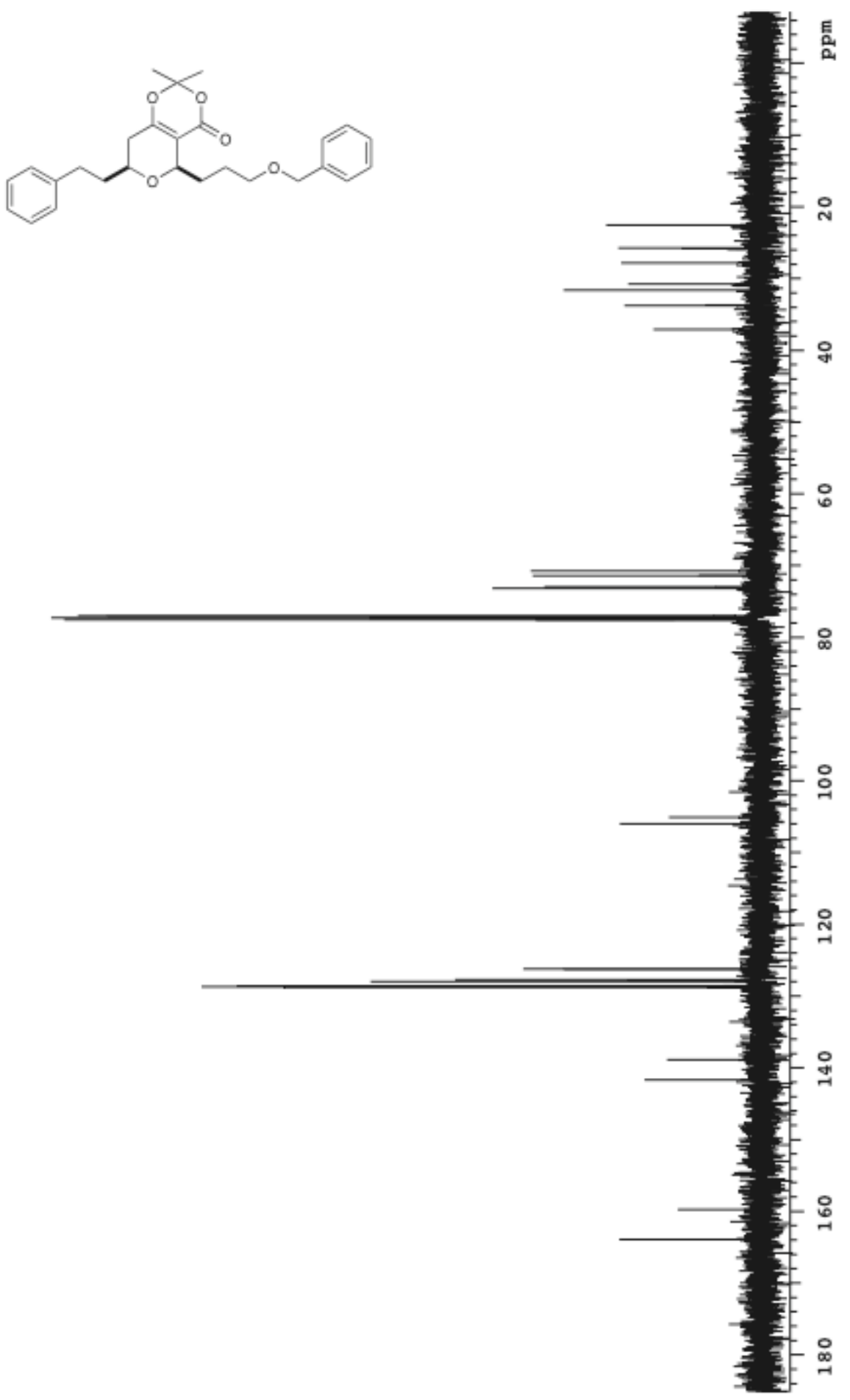


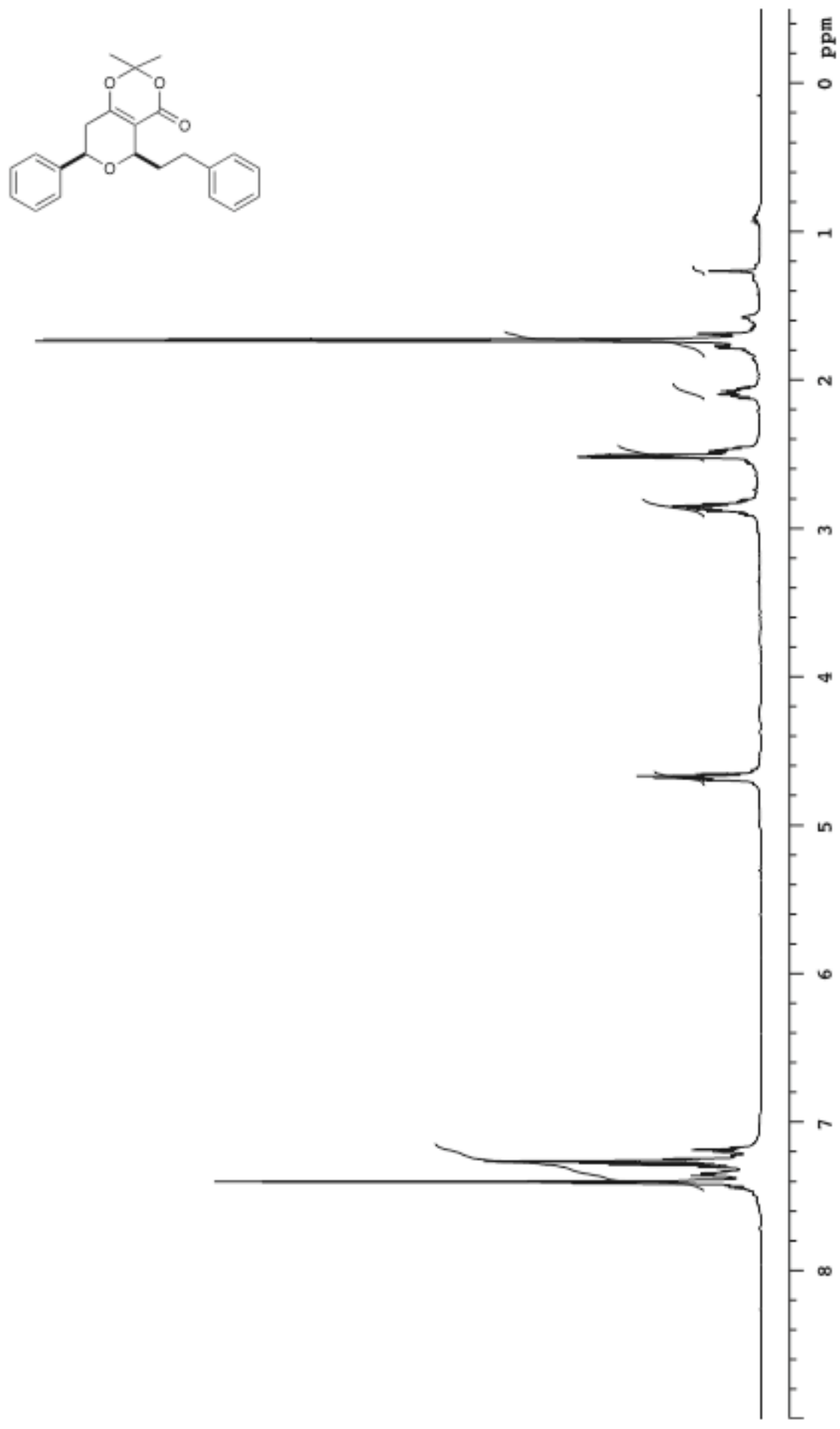


Org. Lett. Supporting Information

Page S26

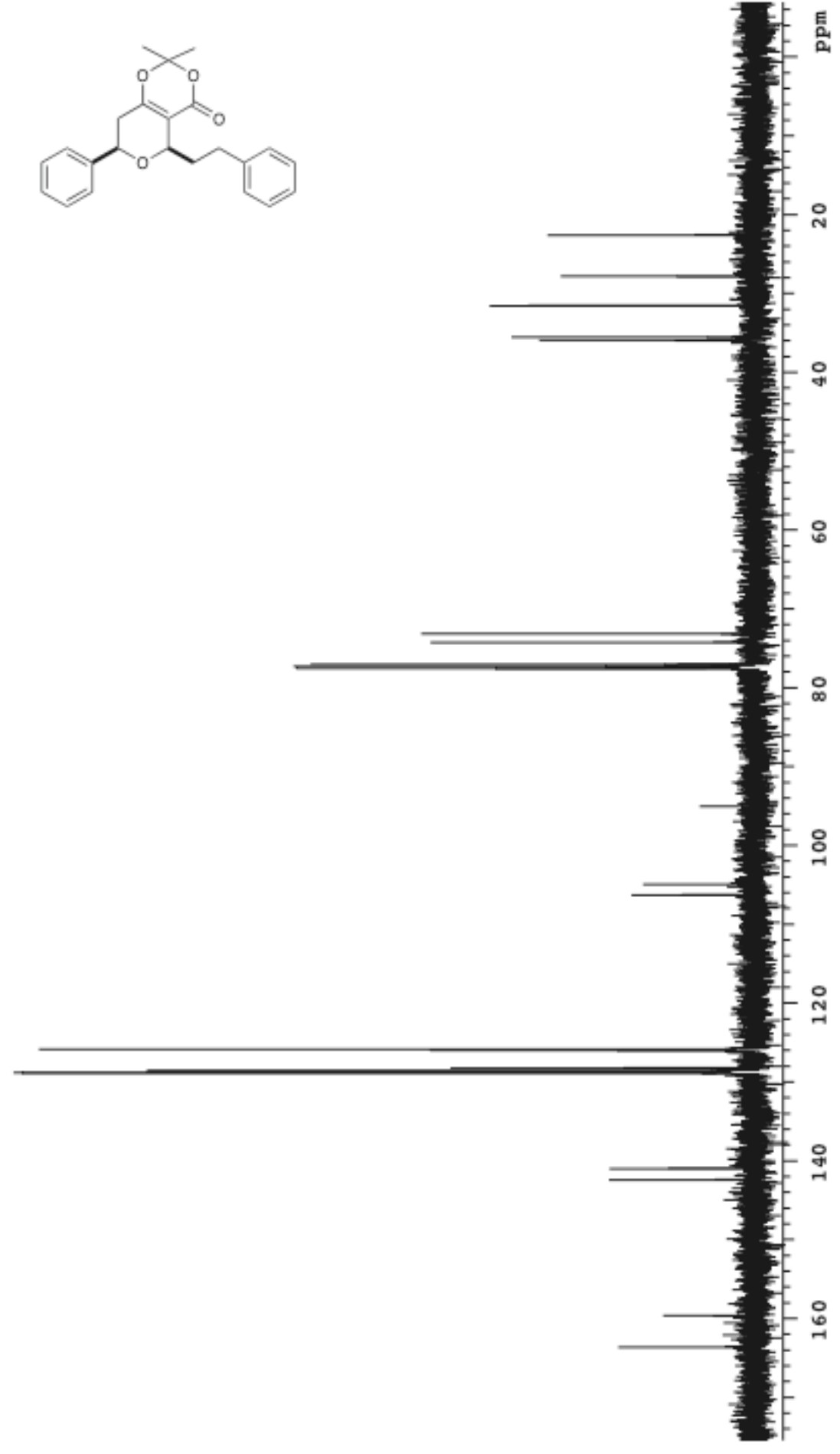




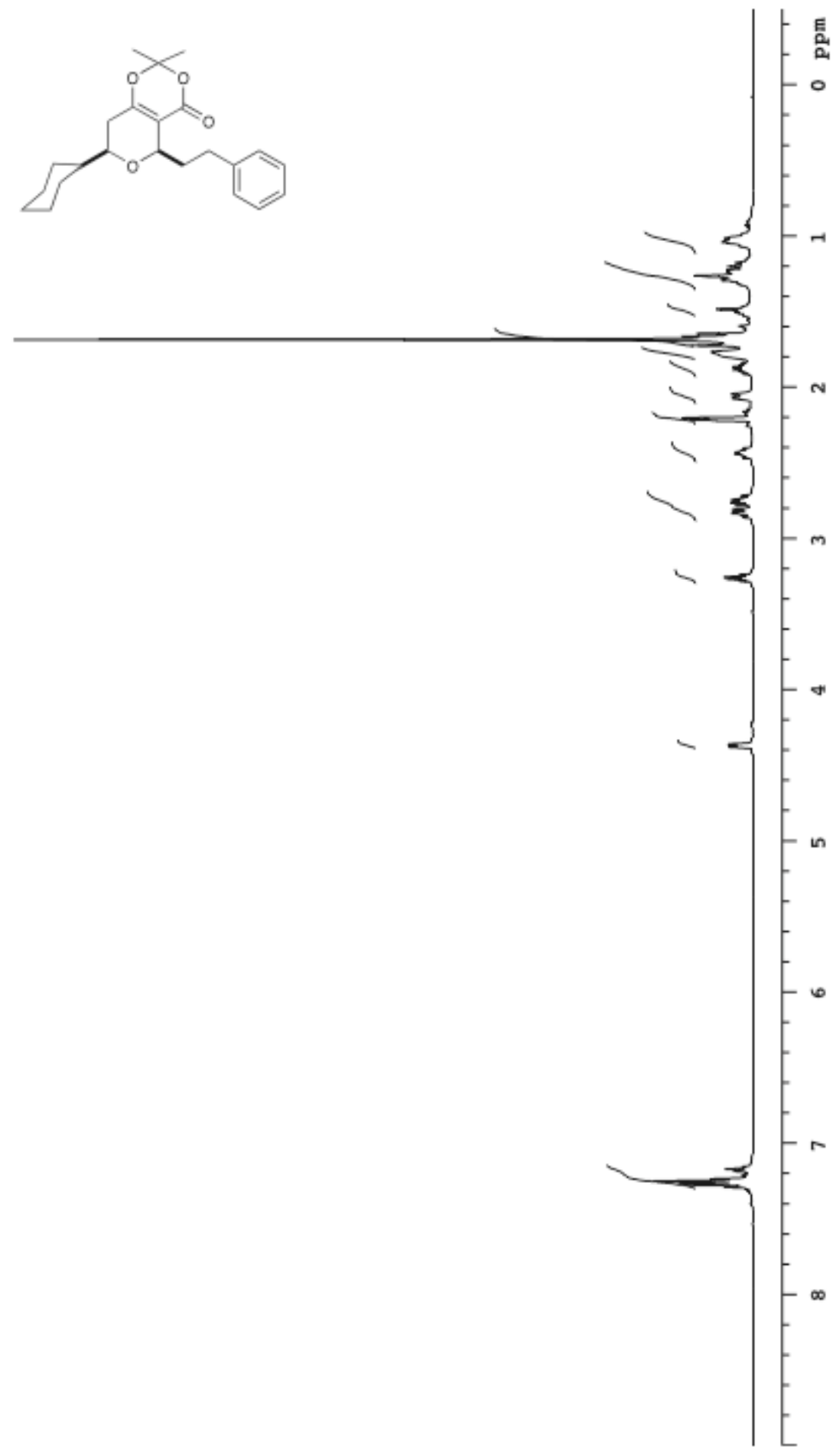




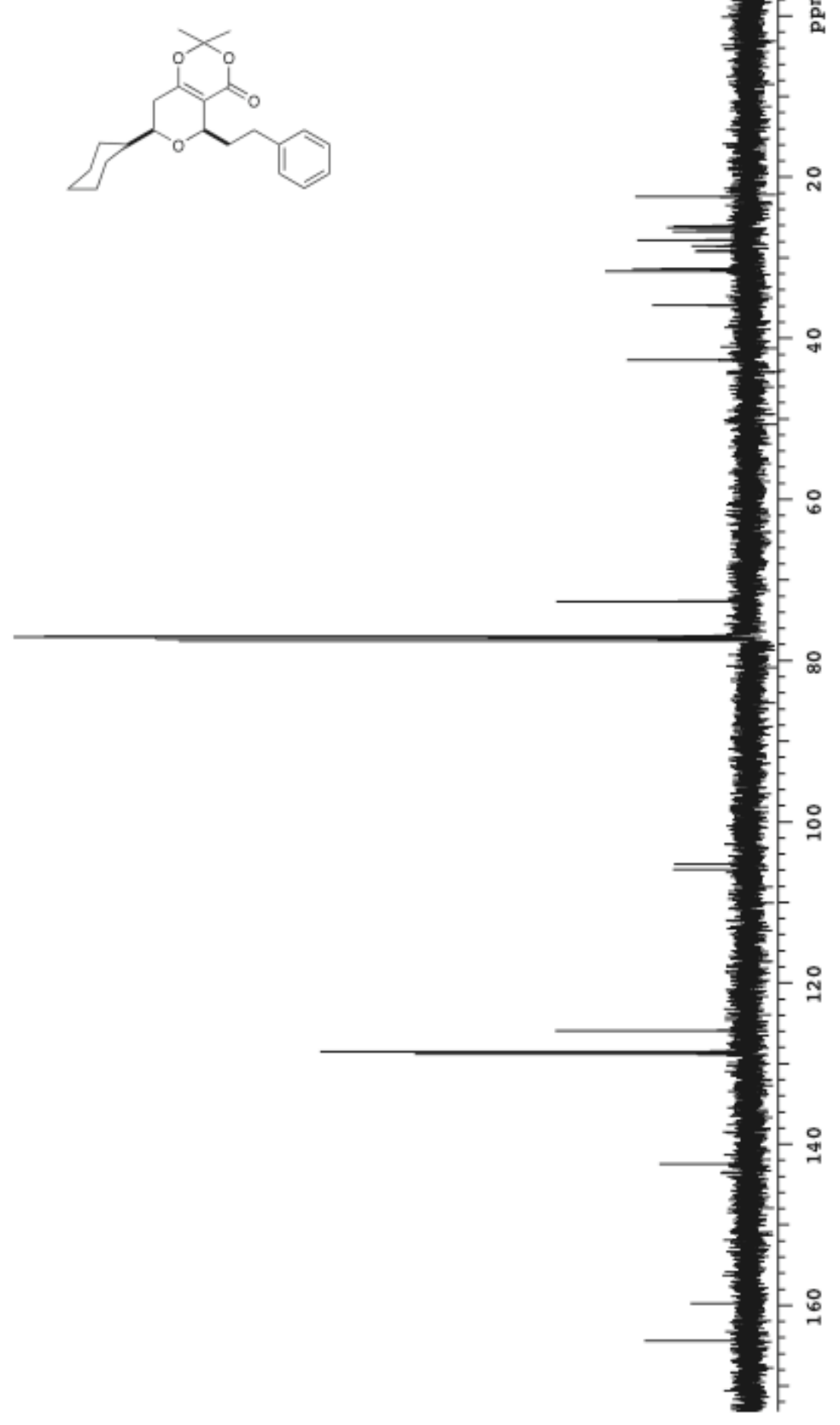




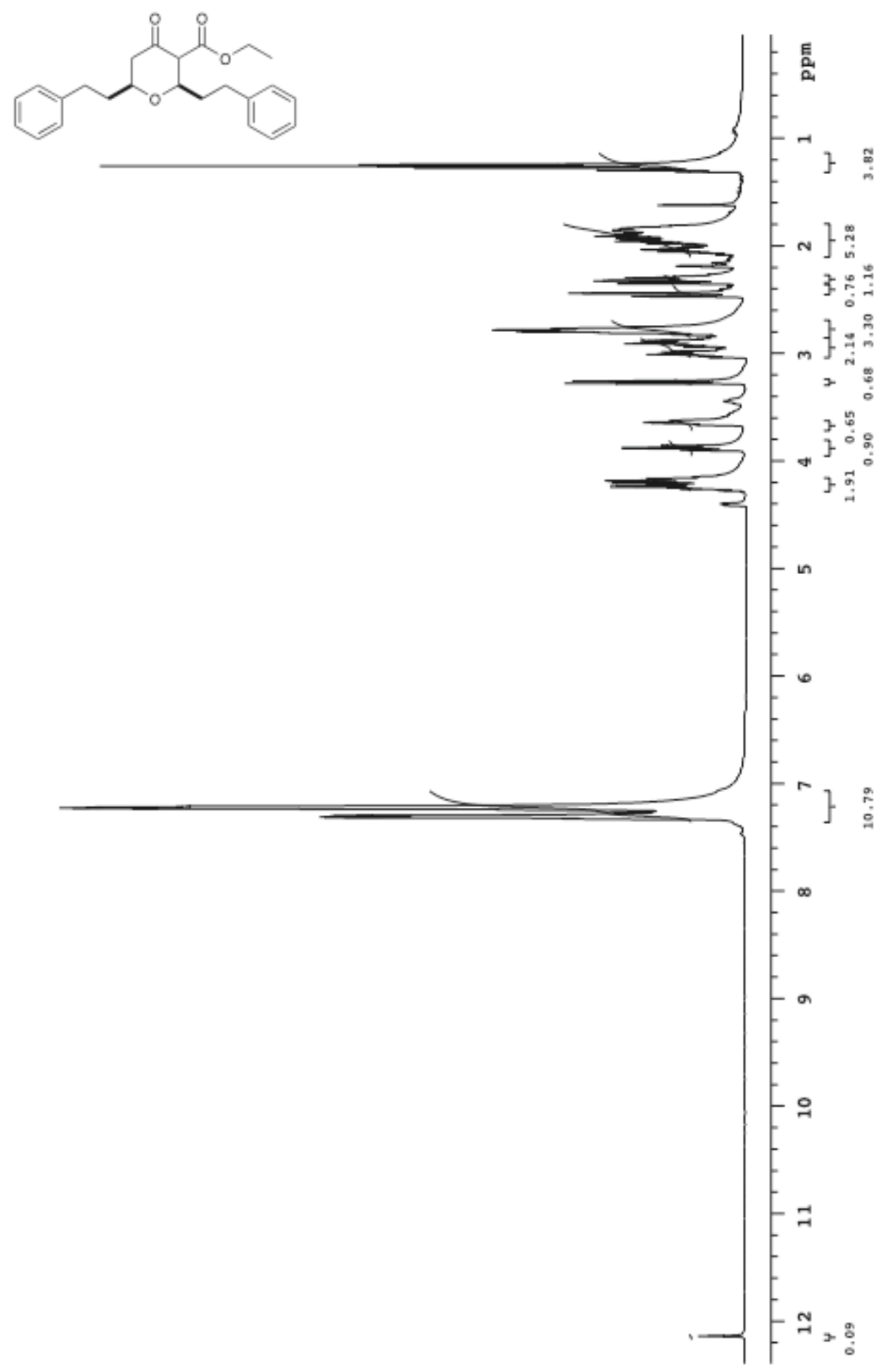



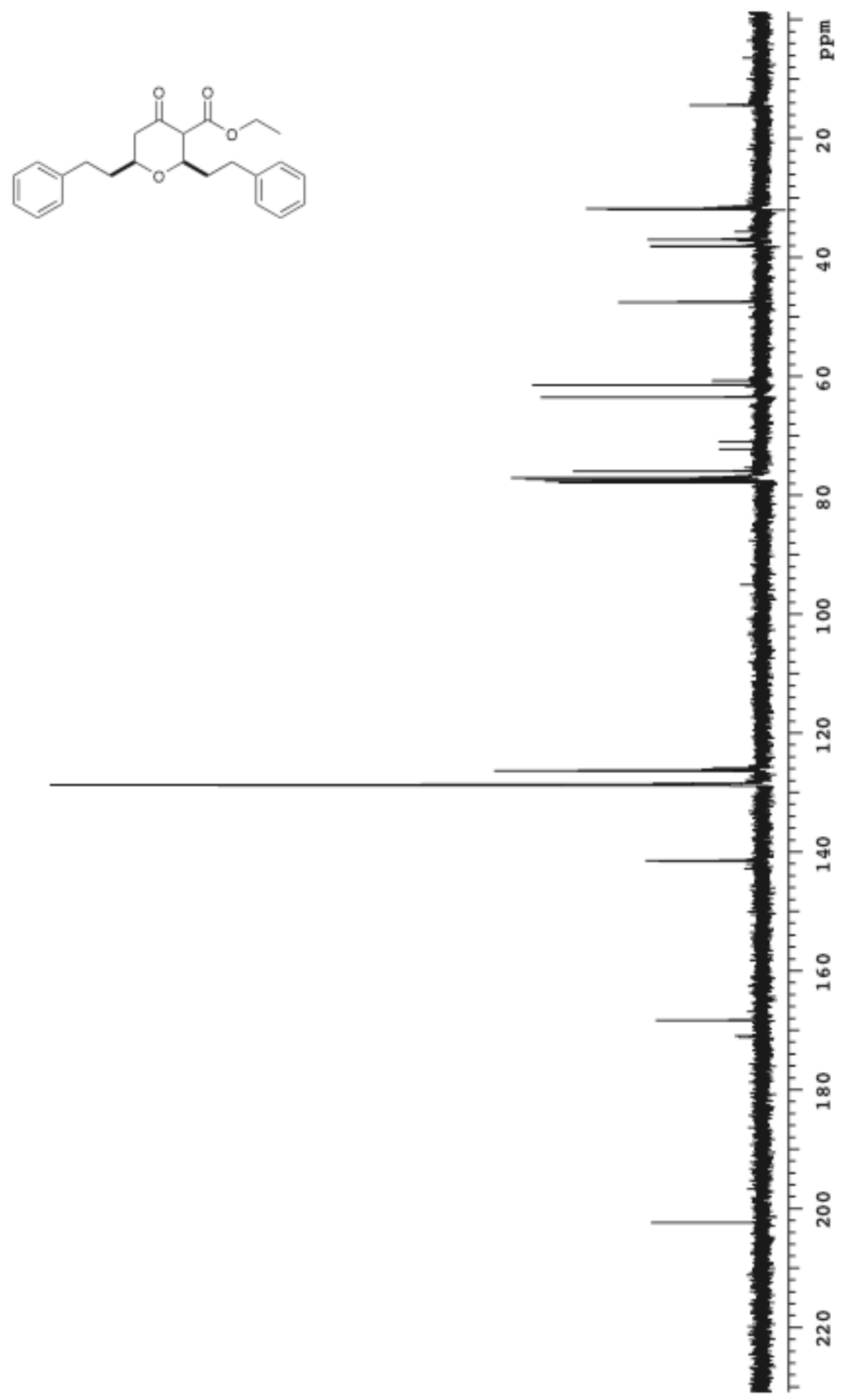


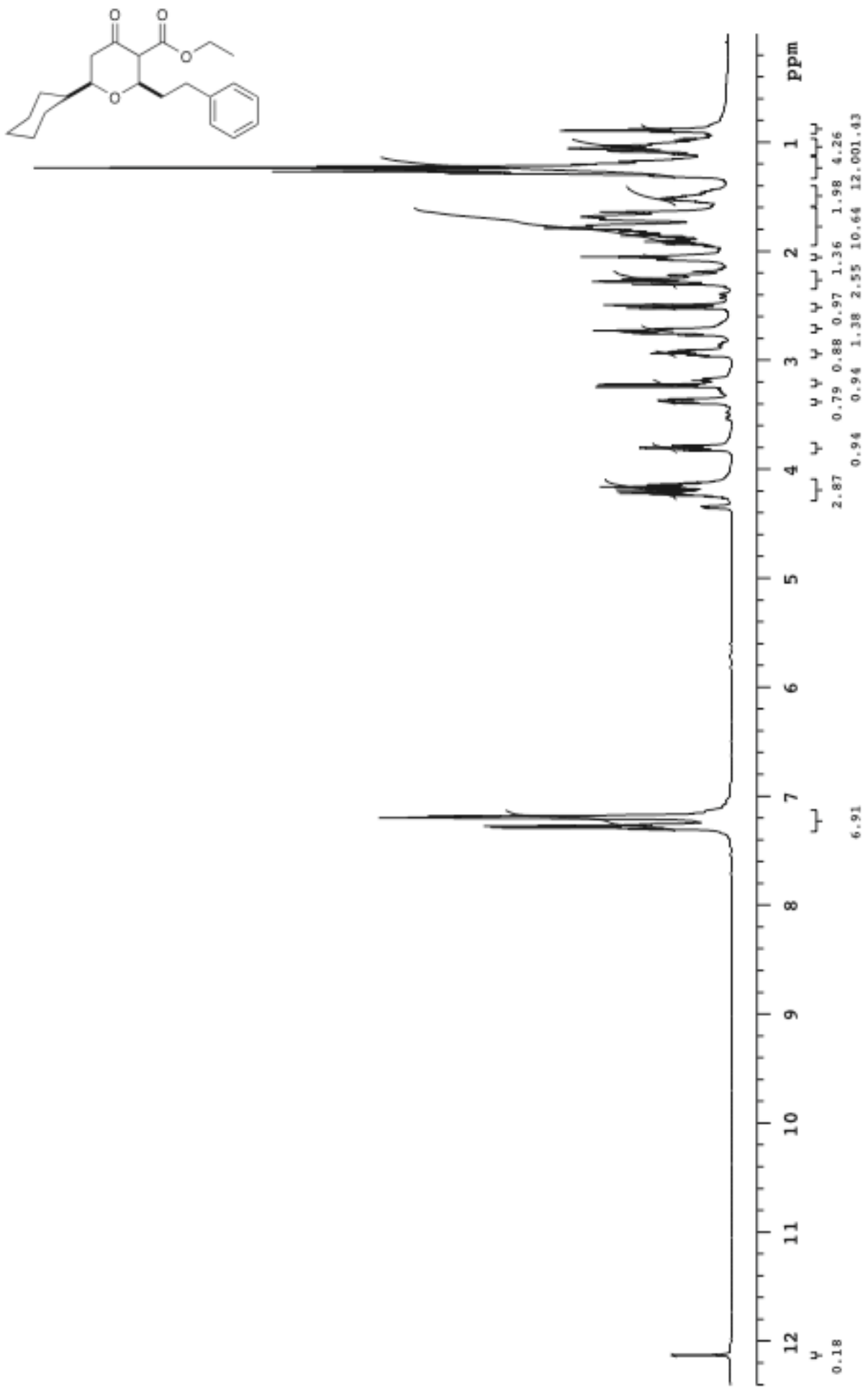




$$
1
$$



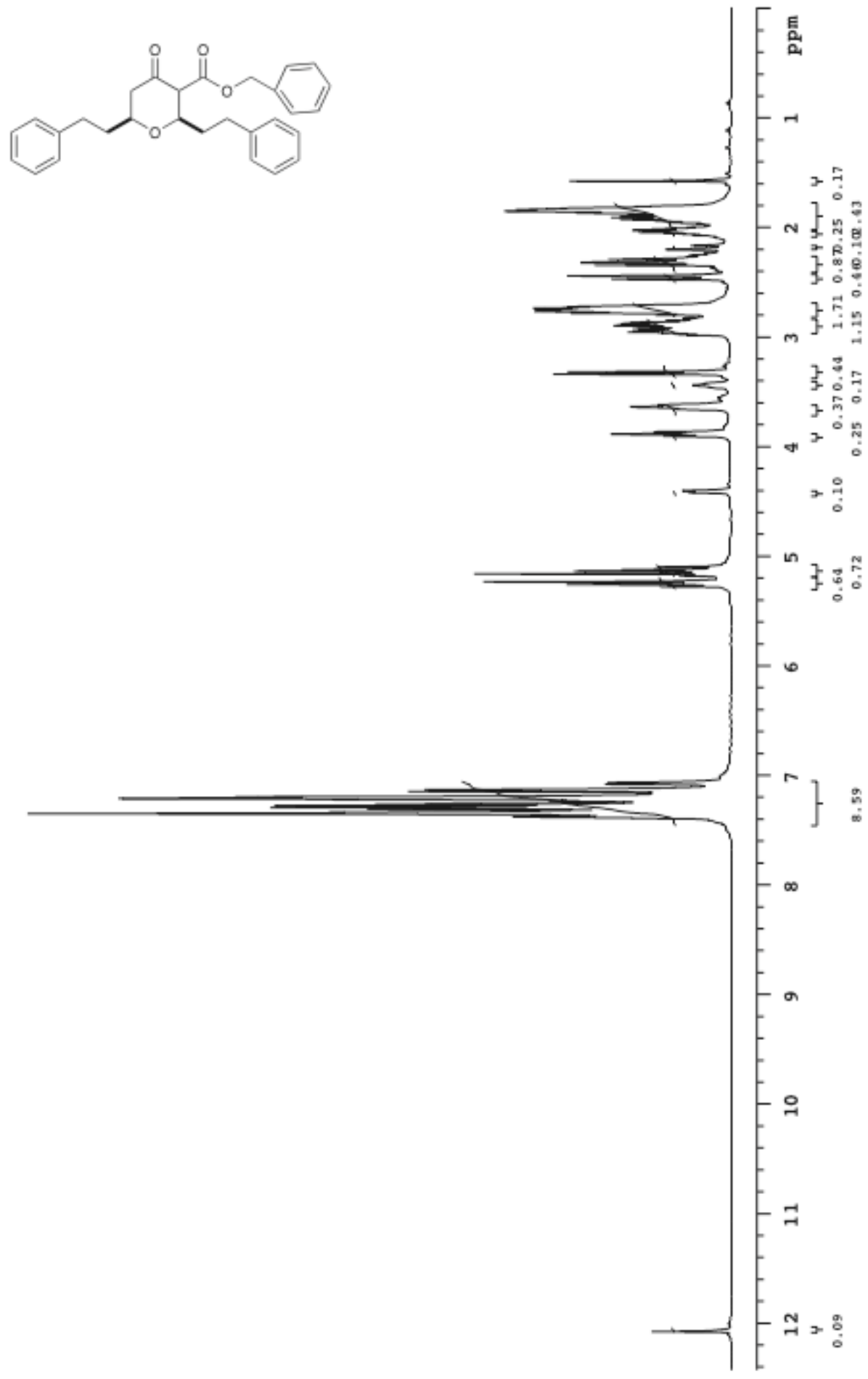
<smiles>O=C1CC(CCc2ccccc2)OC(CCc2ccccc2)C1C(=O)OCc1ccccc1</smiles>

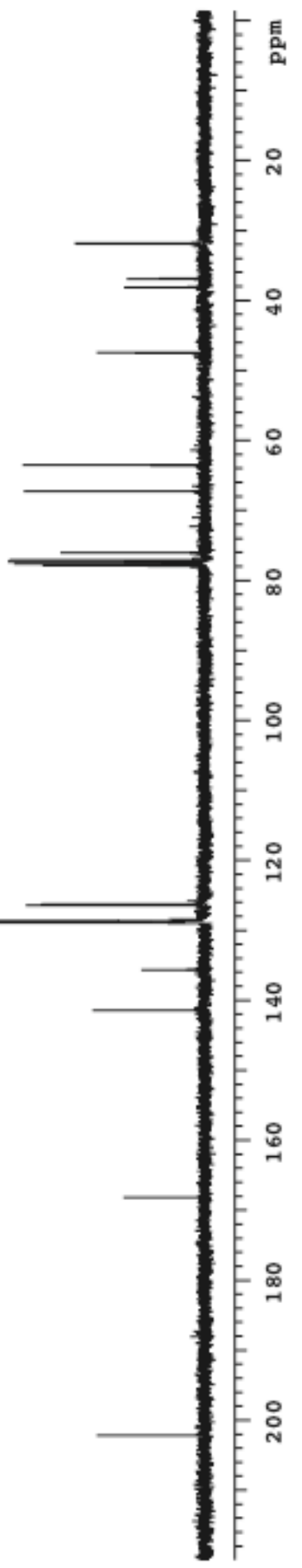




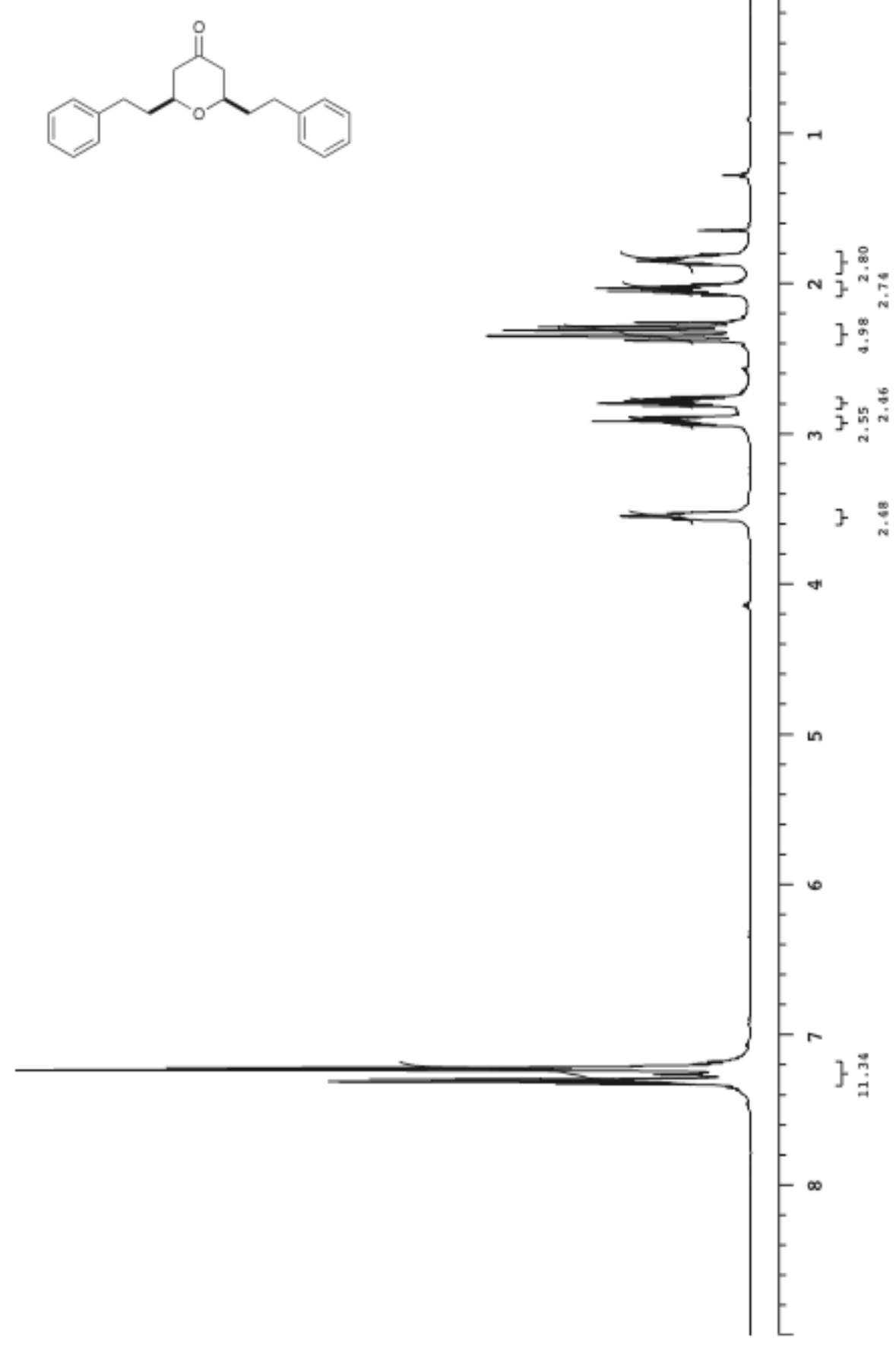




$$
1
$$



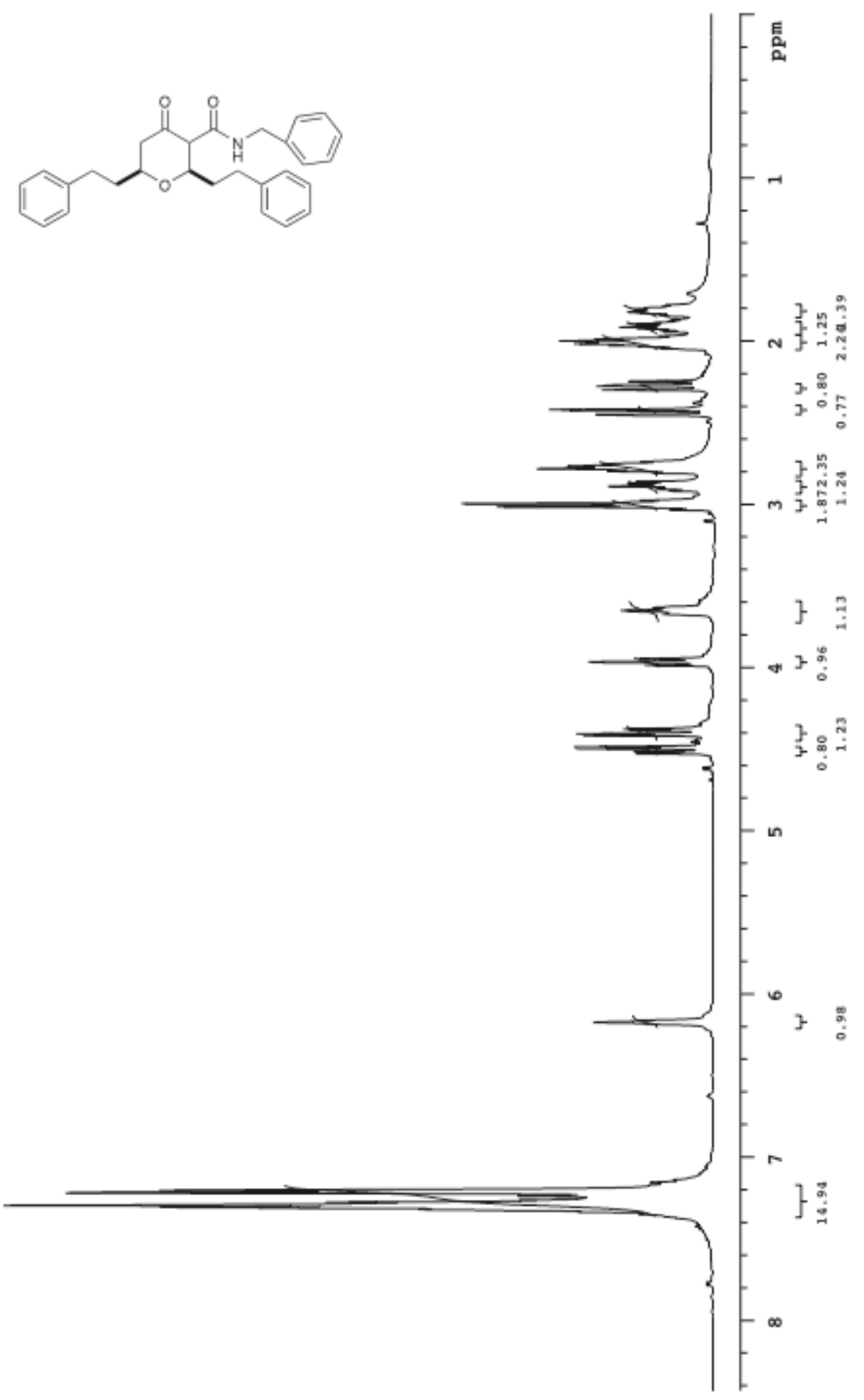


$$
1
$$

